\title{
Humusica 1, article 4: Terrestrial humus systems and forms - Specific terms and diagnostic horizons*
}

\author{
Augusto Zanella ${ }^{a,+, \neq}$, Jean-François Ponge ${ }^{b}$, Bernard Jabiol ${ }^{c}$, Giacomo Sartori ${ }^{d}$, Eckart Kolb ${ }^{e}$, Jean- \\ Michel Gobat ${ }^{f}$, Renée-Claire Le Bayon ${ }^{f}$, Michaël Aubert $^{\mathrm{g}}$, Rein De Waal ${ }^{\mathrm{h}}$, Bas Van Delft ${ }^{\mathrm{h}}$, Andrea \\ Vacca', Gianluca Serra ${ }^{j}$, Silvia Chersich ${ }^{k}$, Anna Andreetta', Nathalie Cools ${ }^{m}$, Michael Englisch ${ }^{n}$, Herbert \\ Hager $^{\circ}$, Klaus Katzensteiner ${ }^{\circ}$, Alain Brêthes ${ }^{p}$, Cristina De Nicola ${ }^{q}$, Anna Testi ${ }^{q}$, Nicolas Bernier ${ }^{b}$, Ulfert \\ Graefe ${ }^{r}$, Jérôme Juilleret ${ }^{\mathrm{s}}$, Damien Banas ${ }^{\mathrm{t}}$, Adriano Garlato ${ }^{\mathrm{u}}$, Silvia Obber ${ }^{\mathrm{u}}$, Paola Galvan ${ }^{\mathrm{v}}$, Roberto \\ Zampedri $^{\mathrm{w}}$, Lorenzo Frizzera ${ }^{\mathrm{w}}$, Mauro Tomasi ${ }^{\mathrm{x}}$, Roberto Menardi ${ }^{\mathrm{a}}$, Fausto Fontanella ${ }^{\mathrm{a}}$, Carmen Filoso ${ }^{\mathrm{a}}$, \\ Raffaella Dibona ${ }^{a}$, Cristian Bolzonella ${ }^{a}$, Diego Pizzeghello ${ }^{a}$, Paolo Carletti ${ }^{a}$, Roger Langohr ${ }^{y}$, Dina \\ Cattaneo ${ }^{a}$, Serenella Nardi ${ }^{a}$, Gianni Nicolini ${ }^{2}$, Franco Viola ${ }^{a}$ \\ a University of Padova, Department TESAF, Padova, Italy \\ ${ }^{\mathrm{b}}$ Muséum National d'Histoire Naturelle, Brunoy, France \\ ${ }^{\mathrm{c}}$ AgroParisTech, Nancy, France \\ d Museo Tridentino di Scienze Naturali, Trento, Italy \\ e Technical University of Munich, Munich, Germany \\ ${ }^{\mathrm{f}}$ University of Neuchâtel, Neuchâtel, Switzerland \\ ${ }^{\mathrm{g}}$ Normandie University, Rouen, France \\ ${ }^{\mathrm{h}}$ Agricultural University of Wageningen, Wageningen, The Netherlands
}

\begin{abstract}
* Humusica 1, article 4 is strongly related to Humusica 1 , article 8 , where a lot of photographs illustrate pedofauna and associated droppings. The presented terms and diagnostic horizons are conceived for understanding the soil functioning. They allow to classify the soil with the morpho-functional key illustrated in Humusica 1 , article 5 .

${ }^{\dagger}$ Corresponding author.

E-mail addresses: augusto.zanella@unipd.it (A. Zanella), ponge@mnhn.fr (J.-F. Ponge), bernard.jabiol@agroparistech.fr (B. Jabiol), giacomo.sartori@sfr.fr (G. Sartori), kolb@wzw.tum.de (E. Kolb), jean-michel.gobat@unine.ch (J.-M. Gobat), claire.lebayon@unine.ch (R.-C.L. Bayon), michael.aubert@univrouen.fr (M. Aubert), rein.dewaal@wur.nl (R.D. Waal), bas.vandelft@wur.nl (B.V. Delft), avacca@unica.it (A. Vacca), Iserra@tiscali.it (G. Serra), silvia.chersich@gmail.com (S. Chersich), anna.andreetta@unifi.it (A. Andreetta), nathalie.cools@inbo.be (N. Cools), michael.englisch@bfw.gv.at (M. Englisch), herbert.hager@boku.ac.at (H. Hager), klaus.katzensteiner@boku.ac.at (K. Katzensteiner), alain.brethes@orange.fr (A. Brêthes), kridn@libero.it (C.D. Nicola), anna.testi@uniroma1.it (A. Testi), bernier@mnhn.fr (N. Bernier), ulfert.graefe@ifab-hamburg.de (U. Graefe), jerome.juilleret@list.lu (J. Juilleret), damien.banas@univ-lorraine.fr (D. Banas), agarlato@arpa.veneto.it (A. Garlato), obbber@arpav.it (S. Obber), paola.galvan@gmail.com (P. Galvan), roberto.zampedri@fmach.it (R. Zampedri), lorenzo.frizzera@fmach.it (L. Frizzera), tomasi@panstudioassociato.eu (M. Tomasi), roberto.menardi@unipd.it (R. Menardi), fausto.fontanella@unipd.it (F. Fontanella), carmen.filoso@unipd.it (C. Filoso), raffaella.dibona@unipd.it (R. Dibona), cristian.bolzonella@unipd.it (C. Bolzonella), diego.pizzeghello@unipd.it (D. Pizzeghello), paolo.carletti@unipd.it (P. Carletti), roger.langohr@ugent.be (R. Langohr), dina.cattaneo@unipd.it (D. Cattaneo), serenella.nardi@unipd.it (S. Nardi), nicolinitrento@gmail.com (G. Nicolini), franco.viola@unipd.it (F. Viola).

${ }^{\ddagger}$ Suggested background music: GYPSY JAZZ/GITAN by Nick Ariondo-Django Reinhardt: https://www.youtube.com/watch?v=jeyORRvVcnk.
\end{abstract}


'University of Cagliari, Cagliari, Italy

${ }^{\mathrm{j}}$ Freelance Researcher, Cagliari, Italy

${ }^{\mathrm{k}}$ Freelance Researcher, Milano, Italy

'University of Florence, Florence, Italy

${ }^{\mathrm{m}}$ Research Institute for Nature and Forest, Geraardsbergen, Belgium

${ }^{\mathrm{n}}$ Bundesamt für Wald, Vienna, Austria

${ }^{\circ}$ Universität für Bodenkultur, Vienna, Austria

${ }^{\mathrm{p}}$ Office National des Forêts, Boigny-sur-Bionne, France

${ }^{a}$ Università La Sapienza, Roma, Italy

${ }^{\mathrm{r}}$ Institut für Angewandte Bodenbiologie, Hamburg, Germany

${ }^{\mathrm{s}}$ Luxembourg Institute of Science and Technology, Belvaux, Luxembourg

${ }^{\mathrm{t}}$ Université de Lorraine, Nancy, France

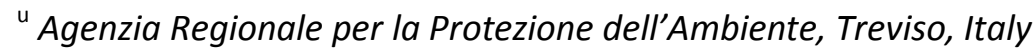

${ }^{\vee}$ Freelance researcher, Trento Italy

${ }^{\mathrm{w}}$ Research and Innovation Centre, Fondazione Edmund Mach, Trento, Italy

${ }^{\mathrm{x}}$ Freelance researcher, Bolzano, Italy

${ }^{y}$ University of Ghent, Belgium

${ }^{2}$ Servizio Parchi e Conservazione della Natura, Provincia Autonoma di Trento, Trento, Italy

Keywords: Humus; Humus classification; Terrestrial humus; Humus diagnostic horizon; Humic component; Recognizable remains; Zoogenically transformed material; Humusica; Humipedon

\section{ABSTRACT}

Knowledge of a little number of specific terms is necessary to investigate and describe humipedons. This "new vocabulary" allows individuating and circumscribing particular diagnostic horizons, which are the fundamental bricks of the humipedon. Few "components" defined by specific terms characterize a specific "humipedon horizon"; few "humipedon horizons" compose a given "humus form" and some similar "humus forms" are grouped in a functional "humus system". In this article, specific terms and humus horizons are listed and explained one by one. Field difficulties are illustrated and resolved. The aim of the article is to present in a manner as simple as possible how to 
distinguish in the field the soil structures allowing a morpho-functional classification of terrestrial (aerated, not submerged) humipedons. 


\section{Introduction}

Léo Lesquereux (1844): « La nature échappe souvent par la diversité de ses créations aux classifications que nous établissons pour la soumettre à notre impuissance».

Humusica recovers specific terms and diagnostic horizons reported in a preceding work, which was written by the same group of authors and can be freely downloaded at:

https://hal.archives-

ouvertes.fr/file/index/docid/561795/filename/Humus Forms ERB 3101 2011.pdf. Each specific term was reconsidered. After discussion, the authors decided to let unchanged a large part of them (terms showing incontestable field affordability) but to improve some crucial definitions related to macro-, meso- and microstructures. In addition, numerous figures accompany the text in the present version, in order to support field investigations and help people faced to a real humus profile and trying to describe and classify humus horizons.

This chapter of Humusica is mainly concerned with forest soils, where a complete sequence of litter and soil horizons can be found and described by picking off successive layers like when turning the pages of a book. Forest soil is often considered as a natural reference for most ecosystems more or less modified by man, including pastures and heaths, being the place where most soil organisms can be found and their activity better exemplified (Callaham et al., 2006). Hence our choice of forest soils for describing specific terms and diagnostic horizons for terrestrial humus forms. However, the reader is referred to two chapters where we made an attempt to classify other terrestrial humus forms and systems, whether in agricultural landscapes (Humusica 2, article 15) or everywhere man created artificial soils (Humusica 2, article 14). We devoted a special part to small-scale disturbances resulting from the activity of wild mammals in forest environments. However, other disturbances may result from land-use change, such as for instance afforestation of agricultural land, primary or secondary succession. This is part of a more general problem, the dynamics and heterogeneity of humus forms, which is treated in Humusica 1, article 7.

\section{Specific terms}

SOIL STRUCTURE. As every observable object, the soil is made of aggregate units themselves built-up by the coalescence of small aggregate sub-units. A level of structure finer than $1 \mathrm{~mm}$ cannot be detected by the naked eye. Using a $10 \mathrm{X}$ magnifying lens, the limit is $0.1 \mathrm{~mm}$. Indeed, in forest and natural soils, a fine granular structure of the A horizon, or even a "single grain" structure, often result from the presence of small arthropod or enchytraeid droppings (purely organic or made of a mixture of organic and mineral matter), in admixture with mineral particles. In our classification, procedure and vocabulary of IUSS Working Group WRB (2015) are adopted, re-elaborated from Soil Survey Staff (2014) and Schoeneberger et al. (2002). Nevertheless, the "normal test" has to be coupled in some cases with a finer analysis in order to: 1) better define finer structures, checking the presence of small animal droppings (see "microstructured" diagnostic A horizon); 2) observe and quantify the presence of structures, concerning only a fraction of the soil mass (secondary structures), which have 
a diagnostic character (e.g., the presence of larger aggregates, resulting from earthworm defecation, in the mass of an A horizon with a very fine granular structure).

ORGANIC HORIZONS. Organic horizons (OL, OF, OH) are formed of dead organic matter (OM), mainly leaves, needles, twigs, roots and, under certain circumstances, other plant material such as mosses and lichens. This OM can be transformed in animal droppings following ingestion by soil/litter invertebrates and/or slowly decayed by microbial (bacterial and fungal) processes (Fig. 1). A limit of $20 \%$ organic carbon (OC) by mass was established to define O horizons (IUSS Working Group WRB, 2015), also adopted in this work, as\% weight of OC in dry samples, without living roots (Method: element analyser, ISO 10390, 1995).

ORGANIC-MINERAL HORIZONS. Organic-mineral horizons (code: A) are formed near the soil surface, generally beneath organic horizons. Coloured by organic matter, these horizons are generally darker than the underlying mineral layer of the soil profile. In the soil fraction $\varnothing<2 \mathrm{~mm}$ of the A horizon, organic carbon has to be less than $20 \%$ by mass following IUSS Working Group WRB (2015).

RECOGNIZABLE REMAINS. Within an organic or organic-mineral horizon = organic remains like leaves, needles, roots, bark, twigs and wood, fragmented or not, whose original organs are recognizable to the naked eye or with a 5-10 X magnifying hand lens. Fresh litter is generally madeup of $100 \%$ recognizable remains (Fig. 2a).

HUMIC COMPONENT of an organic or organic-mineral horizon = small and not recognizable particles of organic remains and/or grains of organic or organic-mineral matter mostly comprised of animal droppings of different sizes. The original plant/animal organs form the litter and generate the small particles (free or incorporated in animal droppings) that are not recognizable to the naked eye or with a 5-10 X magnifying hand lens. Bound mineral particles can be visible within humic component and thus are part of it, beside humified organic matter. Partially or totally, the humic component composes organic-mineral (A) and organic (OL, OF, OH) horizons, indifferently. An A horizon, mostly made of hemorganic (organic-mineral) anecic and endogeic earthworm droppings, as well as a finely humified and mostly organic $\mathrm{OH}$ horizon resulting from epigeic earthworm, enchytraeid and microarthropod activities, are both composed of humic component ( $100 \%$ or close to, Figs. $2 b$ and $c$ ), despite differences in the animal activities responsible for the structure of these horizons. Humic component, based on the direct observation of humus profiles by the naked eye, must not be confounded with "humified organic matter", based on the chemical extraction of humic compounds from soil horizons, hence on the destruction of the humic component.

MINERAL COMPONENT of an organic or organic-mineral horizon = mineral particles of different sizes, free or very weakly bound to humic component and visible to the naked eye or with a 5-10 X magnifying hand lens.

ZOOGENICALLY TRANSFORMED MATERIAL = recognizable remains and humic component processed by animals, i.e. leaves, needles and other plant residues more or less degraded by soil animals, mixed within their droppings (Fig. 2a-c). A finely powdered and/or granular structure (less than $1 \mathrm{~mm}$ ) is typical of the terminal stage of faunal attack in an organic horizon. At this last level of biotransformation, the substrate ( $\mathrm{OH}$ horizon) is essentially comprised of organic animal droppings of various sizes (droppings of epigeic earthworms, of macroarthropods such as millipedes, woodlice and 
insect larvae, of microarthropods such as mites and springtails, and of enchytraeids dominate). Within organic-mineral horizons, animal activity leads to different types of A horizons, depending on the animal's ability to dig the mineral soil and to thoroughly mix organic and mineral matter. Zoogenically transformed material may be active (currently inhabited by living animals, freshly transformed, with recent droppings, grazing marks or tunnels) or inactive (without living animals or recent signs of animal activity, aged 1-2 years or more). The massive and plastic organic endpoint of biological transformation in the sequence of organic horizons ( $\mathrm{OL} \rightarrow \mathrm{OF} \rightarrow \mathrm{OH}$ ) is classified as inactive zoogenically transformed material.

NON-ZOOGENICALLY TRANSFORMED MATERIAL = recognizable remains and humic component processed by fungi or other non-faunal processes, i.e. leaves, needles and other plant residues more or less fragmented and transformed into fibrous matter by fungi (Figs. 3a and $b$ and 4b). Recognizable recent animal droppings are absent or not detectable by the naked eye in the mass. Fungal hyphae can be recognized as white, brown, black, or yellow strands permeating the organic or organic-mineral substrate. Traces of animal activity (droppings, old bite marks, mucus) may sometimes be detectable but are always marginal. In the last stage of biodegradation of an organic horizon, non-zoogenic substances may essentially be composed of dry, brown plant residues more or less powdered or finely fragmented. Non-zoogenically transformed material is in any case inactive material that exhibits low biological activity. It concerns organic horizons showing strong fungal attack (often due to white rot activity), or non-zoogenic organic-mineral horizons with massive or single-grain structure sometimes overrun by fungal hyphae.

LITTER. This word is commonly used while speaking of more or less decomposed organic matter (leaves, needles, little branches...) laying at the surface of the soil. Generally, it consists in OL and OF (zoogenically or non-zoogenically transformed) horizons as defined in this article. In order to avoid confusion, it is preferable to use standardized soil diagnostic horizons.

HUMUS. This word is commonly used while speaking of well decomposed organic matter laying at the surface of the soil, or present in the first $30 \mathrm{~cm}$ of it. Often it consists in OF and $\mathrm{OH}$ horizons or very rich in organic matter $(O C>10 \%)$ A horizons as defined in this article. In order to avoid confusion, it is preferable to use standardized soil diagnostic horizons.

\section{Definition of diagnostic horizons}

A minimum thickness of horizons for description, diagnosis and sampling purposes has been established at $3 \mathrm{~mm}$. Below this threshold, the horizon is considered discontinuous if clearly in patches or absent if indiscernible from other neighbouring horizons. The vagueness of transitions between organic and organic-mineral horizons (or mineral ones, in the absence of an organic-mineral horizon) is an important diagnostic character. Three scales of transition have been adopted: very sharp transition within less than $3 \mathrm{~mm}$, sharp transition between 3 and $5 \mathrm{~mm}$ and diffuse transition if over more than $5 \mathrm{~mm}$. 
In this guide, the use of letters-indices is limited to small letters added as prefixes, avoiding confusion with soil-reference suffixes (ex. $\mathrm{nOL}=\mathrm{OL}$ horizon composed of $\mathrm{n}=$ new litter, age $<1$ year, neither fragmented nor transformed/discoloured litter). These prefixes are also listed in Table 1.

\subsection{Organic horizons (O horizons)}

Roots being excluded, organic horizons have been grouped in three diagnostic horizons, OL, $\mathrm{OF}$ and $\mathrm{OH}$ according to the rate of recognizable remains and humic component (Fig. 4a). Suffixes are used to designate specific kinds of organic horizons then detailed into types. At present, names and suffixes of these organic horizons are not in line with proposals from IUSS Working Group WRB (2015) or Soil Survey Staff (2014). Historical discrepancies and habits still prevent a common nomenclature. However, the following approximate correspondence can be established: $\mathrm{OL}=\mathrm{Oi} ; \mathrm{OF}=$ $\mathrm{Oe} ; \mathrm{OH}=\mathrm{Oa}$.

OL (from Organic and Litter). Horizon characterized by the accumulation of mainly leaves/needles, twigs and woody materials. Most of the original plant organs are easily discernible to the naked eye. Leaves and/or needles may be discoloured and slightly fragmented. Humic component amounts to less than $10 \%$ by volume; recognizable remains $10 \%$ and more, up to $100 \%$ in non-decomposed litter (Figs. 5 and 6).

OL types (prefixes: $n, v)$ :

- $\mathrm{nOL}=$ new litter (age $<1$ year), neither fragmented nor transformed/discoloured leaves and/or needles (Fig. 5a-e);

- $\quad \mathrm{VOL}=$ old litter (aged more than 3 months, vetustus, verändert, verbleicht, vieillie), slightly altered, discoloured, bleached, softened up, glued, matted, skeletonized, sometimes only slightly nibbled by fauna (Figs. 6a-e);

Remarks:

- the passage from OLn to OLv can be very rapid (1 to 3 months) or very slow (more than a year) according to litter types (plant species composition), climate, season and level of soil biological activity;

- a beech leaf may be spotted due to fungal infection, without losing its integrity, thus while still belonging to the $\mathrm{OL}$ horizon.

OF (from Organic and Fragmented or inappropriately 'fermented'). Horizon characterized by the accumulation of fragmented, bleached, and/or skeletonized leaves and/or needles, without any entire plant organ to the exception of recalcitrant plant remains such as twigs and bark pieces. The proportion of humic component is $10 \%$ to $70 \%$ by volume (Fig. 4 a). Depending on the humus form, decomposition is mainly accomplished by soil fauna (zoOF) or cellulose-lignin decomposing fungi (nozOF, Fig. 4b). Slow decomposition is characterized by a partly decomposed matted layer, permeated by hyphae. Rapid decomposition is characterized by the deposition of animal faeces, often in layers between leaf and needle fragments. Fine roots (often with upward growing 
mycorrhizal tips in forests) are often present, indicating that this horizon is not only the main seat of organic matter recycling through faunal and microbial activity but also the main seat of plant nutrient uptake. Note that most soil fungal mycelia (including mycorrhizal fungi) are white- or yellowcoloured: bleaching is indicated by the colour of plant remains, not by the colour of fungal parts.

OF types (prefixes: zo, noz):

zoOF $=$ content in zoogenically transformed material: $>10 \%$ of the volume of the horizon, roots excluded (Figs. 4b, 7a-d);

nozOF = content in non-zoogenically transformed material: $90 \%$ or more of the volume of the horizon, roots excluded (Figs. 8a-c);

Remark: the ratio zo/noz in transformed material can exhibit relatively important seasonal variation.

OH (from Organic and Humus, humification, implicit zoOH). Horizon characterized by an accumulation of zoogenically transformed material, i.e. black, grey-brown, brown, reddish-brown more or less aged animal droppings. A large part of the original plant organs are not discernible, the humic component amounting to more than $70 \%$ by volume. $\mathrm{OH}$ differs from OF horizon by a more advanced transformation of litter (fragmentation, humification, etc.) due to the action of soil organisms (Figs. 2b, 4a, 9a-d).

$\mathrm{OH}$ type (prefix: szo): szoOH = slightly zoogenic $\mathrm{OH}$ (Fig. 9e). $\mathrm{OH}$ is always zoogenic in origin (implicit zoOH). However, pedofauna may disappear by lack of fresh substrates to be eaten, most faunal activity then taking place in the overlying zoOF horizon. By observing carefully the $\mathrm{OH}$ horizon it is possible to see remains of past faunal activity in the form of droppings, corpses, bitten leaf fragments, etc. However, sometimes this abandoned horizon is invaded by fungal mycelia and lack traces of animal activity, while it still cannot be confused with nozOF in which recognizable remains (pieces of leaves or needle) always dominate over humic component (faecal organic matter). The ascension of water in seasonally waterlogged soils may also change the appearance of the $\mathrm{OH}$ horizon (see Humusica 2, article 11).

\subsection{Organic-mineral horizons (A horizons)}

The different diagnostic $A$ horizons are identified in the field by observing the soil mass by the naked eye or with a 5-10 X magnifying hand lens, assessing structure (Soil Survey Staff, 2014; Schoeneberger et al., 2012; FAO, 2006) and consistence, and measuring $\mathrm{pH}_{\text {water }}$ according to ISO 10390 (2005) with a portable electrode (Adamchuk et al., 2004). Easier to measure in the field, $\mathrm{pH}_{\text {water }}$ is less stable than $\mathrm{pH}_{\mathrm{CaCl} 2}$ or $\mathrm{pH}_{\mathrm{KCl}}$, which are generally measured in the laboratory and show values about 1 unit lower. Five diagnostic $A$ horizons may be distinguished (Fig. 10):

- Zoogenic A horizons

- Zoogenic A horizon (code: zoA) = maA (implicit zomaA) or meA (zomeA) or miA (zomiA): 
- Biomacrostructured $\mathrm{A}(\mathrm{maA})=$ Aneci-endovermic bio-horizon;

- Biomesostructured A (meA) = Endo-epivermic bio-horizon;

- Biomicrostructured A (miA)= Enchy-arthropodic bio-horizon.

- Non-zoogenic A horizons

- nozA = A horizon considered as non-zoogenic. To the naked eye, or with the help of a hand lens, this horizon does not show relevant signs of animal activity (absence of burrows; droppings, mucus coatings, animal remains, etc. $<5 \%$ of soil volume). Zoological agents are not involved in soil aggregation. Fungus- and root-derived aggregates can be visible. nozA = sgA (implicit nozsgA) or msA (nozmsA):

- Single grain A (sgA);

- Massive A (msA).

Biomacro and biomesostructured horizons belong to a group of zoogenic horizons made of "well amalgamated" humic component, i. e. humic component generated by macroannelids or macroarthropods whose faeces are well mixed organic-mineral aggregates. The proportion of anecic or large endogeic earthworms within the burrowing population will decide whether horizons will be biomacrostructured or biomesostructured. We propose a key of classification of these aggregates related to the size of animals that generate the original droppings (Fig. 20). When anecic or large endogeic earthworms are abundant enough (whether geographically or seasonally) the proportion of macroaggregates overwhelms that of mesoaggregates. Macrostructure is typical of Mull and Amphi systems, but Mull and Amphi humus forms may show biomesostructured A horizons in base-poor soils. There are biomeso Amphi humus forms in which a large amount of thin roots is associated to biomesostructured A horizons. In base-rich soils of Mediterranean forests, the A horizon is often biomesostructured. In Alpine spruce forest ecosystems, a dynamic succession of Moder and Amphi is accompanied by a sequence of biomicro and biomacro $A$ horizons which alternate along successive forest cycles. In agricultural soils, the addition of compost or tillage or pesticide/fertilizer treatment may influence the size of soil aggregates through changes in soil animal activity.

People may use step-by-step references rigorously outlined in the following frame, using the same display as FAO manuals. The term "ped" is used with the meaning of "soil aggregate" independently of its origin which can be biological or not:

Biomacrostructured $\mathbf{A}$ horizon (Code: $\mathrm{maA}$ ) =aneci-endovermic $\mathrm{A}$ horizon. To be identified as a biomacrostructured $A$ horizon (maA), a layer must display at least four of the following properties (Figs. 11a-g):

- structure (FAO, 2006): never lack of structure, i.e. never lack of "built" structure;

- structural grade (FAO, 2006): moderate or strong; size if of granular shape: medium (2-5 $\mathrm{mm})$ and/or coarse; size if of subangular blocky shape: fine $(5-10 \mathrm{~mm})$ or very fine $(<5 \mathrm{~mm})$;

- presence of peds, observable in place in undisturbed soil as well as after gently squeezing a sample of soil in hand palm: all sizes of peds are present and make more than $1 / 3$ of soil 
volume, and volume of biological macropeds $(\oslash>4 \mathrm{~mm})$ rising at least $1 / 3$ of the volume of all biological peds;

- living earthworms, or earthworm burrows and/or casts;

- earthworm burrows within the underlying horizon;

- pHwater $>5$.

Biological description: the whole horizon is made-up of more or less aged anecic and large endogeic earthworm droppings (the limit of $4 \mathrm{~mm}$ is rarely reached by droppings of arthropods and epigeic or small endogeic earthworms); roots and fungal hyphae (visible or not) also play an important role in the formation and stability of aggregates. Living earthworms are always present but not always observable in humus profiles at the time of sampling. However their burrows and casts are always present within the horizon (Hamilton and Sillman, 1989).

In dry Mediterranean environments, biomacrostructured A horizons from subterranean beetle activity (Tenebrionidae) have also been observed (Peltier et al., 2001). In sub-tropical or tropical areas, termites or ants or even crabs can generate biomacrostructured A horizons (Figs. 11eg). Moles can also contribute to the formation of a soil macrostructure by excavating topsoils previously worked by earthworms or arthropods. A poorly zoogenic macrostructured A horizon is presented in Figure $11 \mathrm{~h}$ for the sake of comparison. In this case aggregates, which are mainly made of aged and reworked annelid faeces, have a very variable shape, often polygonal (blocky structure of FAO manuals, see Table 2). The soil looks like a block that casually broke in many irregular fragments. The annelid origin of fine $(5-10 \mathrm{~mm})$ and very fine $(<5 \mathrm{~mm})$ blocky structures found in A horizons has been suggested by micromorphological studies following the ageing and coalescence of earthworm and enchytraeid faeces along agricultural and forest soil profiles (Jongmans et al., 2001; Mori et al., 2009).

Biomesostructured $\mathbf{A}$ horizon (Code: $\mathrm{me} A$ ) = endo-epivermic $\mathrm{A}$ horizon. The biomesotructured A horizon (meA) displays all of the following properties (Figs. 12a-c):

- never lack of structure;

- structural grade (FAO, 2006): weak to moderate or strong (rarely weak); size if granular shape: fine (1-2 $\mathrm{mm}$ ) and/or medium $(2-5 \mathrm{~mm})$; size if subangular blocky shape: very fine $(<$ $5 \mathrm{~mm}$ );

- $\quad$ presence of peds, observable in place in undisturbed soil as well as after gently squeezing a sample of soil in the hand palm: various sizes of peds are present and make more than $1 / 3$ of soil volume and volume of mesopeds (from 1 to $4 \mathrm{~mm}$ ) greater than the volume of macropeds ( $>4 \mathrm{~mm}$ ); the biomesostructure is sometimes defined by exclusion of the other biostructures: if a biostructure does not follow the criteria of macro- (macropeds $\geq 1 / 3$ of volume) or microstructure (micropeds $\geq 2 / 3$ vol), while being not single-grain or massive, then it most probably corresponds to a mesostructure;

- living epigeic and small endogeic earthworms, macroarthropods or large enchytraeids or their droppings.

Biological description: earthworms (mostly epigeic and small endogeic), large enchytraeids and macroarthropods (even in larval stages) are responsible for the structure; roots and fungal hyphae are also involved. Anecic and large endogeic earthworm droppings, classified typically as 
biomacro peds, are subordinate, allowing the expression of the structuring activity of smaller organisms. Biological peds made by earthworms are well amalgamated structures. Their components are well mixed in the homogeneous silty-clayish paste, mineral grains included in the paste are rarely visible by naked eye, but could be visible with the help of a $10 \mathrm{X}$ lens. In dry Mediterranean, biomeso and biomacrostructured $A$ horizons from subterranean beetle activity (Tenebrionidae) have been also observed (Peltier et al., 2001). In subtropical or tropical areas termites or ants are able to originate biomacro- and biomesostructured $\mathrm{A}$ horizons.

Biomicrostructured $\mathbf{A}$ horizon (Code: $\mathrm{mi} A)=$ enchy-arthropodic $\mathrm{A}$ horizon. The biomicrostructured A horizon (miA) displays at least four of the following properties (Figs. 13a and b):

- absence of peds $>4 \mathrm{~mm}$; peds make more than $10 \%$ of soil volume observable both in situ, in undisturbed soil, and after gently squeezing a sample of soil in the hand palm, and volume of micropeds ( $\leq 1 \mathrm{~mm}$ ) rising at least $2 / 3$ of the volume of all peds; gently squeezing the soil, almost all large peds are easily reduced into smaller units;

- structural grade (FAO, 2006): moderate, strong; shape: granular; size: very fine ( $<1 \mathrm{~mm})$;

- possible presence of uncoated sand grains;

- $\quad \geq 10 \%$ organic particles and dark-coloured biogenic peds (holorganic or hemiorganic peds =humic component);

- living microarthropods, small enchytraeids or their droppings.

Biological description: the horizon displays an important amount of tiny organic-mineral faecal pellets, droppings of enchytraeids (potworms), microarthropods (larval stages of small insects, mites, springtails, etc.) and small non-recognizable remains of decomposed litter. This horizon is observed on silt loamy soils. Hyphae and roots are also very common.

Because of observable processes of initial pedogenesis, the horizon could also be defined as miAC. The fragmented rock may be siliceous or calcareous.

Single-grain A horizon (Code: $\mathrm{sgA}$ ). To be identified as a single-grain A horizon ( $\mathrm{sgA}$ ), a layer must display at least four of the following properties (Fig. 14):

- undisturbed soil mass: unbound loose consistence; dominance of sand grains (mineral component $\geq 50 \%$ );

- structure (FAO, 2006): single grain;

- presence of clean (=uncoated) sand grains;

- $\quad<10 \%$ of fine organic particles and/or dark-coloured biogenic (holorganic or hemorganic) peds;

- mineral grains coated with organic matter indicate a process of in situ podzolization (incipient Bh horizon, Nierop and Buurman, 1999);

- faecal pellets of micro-arthropods or enchytraeids are sometimes present $(<10 \%)$.

Because of observable processes of eluviation or illuviation (Guillet et al., 1975), the horizon could be defined as SgAE (or sgEA) or SgAB following its similarity with mineral horizons. E horizons are mineral horizons in which the dominant process responsible for their formation is the loss of silicate clay, iron, aluminium, or some combination of them, leaving a high concentration of sand and silt particles, and in which all or much of the original rock structure has been obliterated(FAO, 2006). 
Massive A horizon (Code: $\mathrm{ms} A$ ). To be identified as a massive $A$ horizon $(\mathrm{ms} A)$, a layer must display at least three of the following properties (Fig. 15):

- undisturbed soil matrix: heterogeneous but one-piece, no planes or zones of weakness (cracks) are detectable in the mass;

- structure (FAO, 2006): massive. If the soil is dry, when applying moderate to strong pressure with fingers, the soil sample progressively breaks up into finer artificial units; these fine units have a varying mineral, organic-mineral or organic composition; if the soil is moist, the sample can be transformed into tender, plastic, nonelastic matter;

- presence of uncoated sand grains. A 5-10x magnifying hand lens is necessary to detect the composition of the pellets or grains (animal droppings $<5 \%$ of the soil volume), the size of commonest biostructured units being $<1 \mathrm{~mm}$;

- $\quad$ pHwater $<5$.

Cohesion forces among soil components appear equally distributed in the soil, as they depend mostly on physical or chemical bonds rather than biological aggregation. Past biological activity can have also been active in the process of formation of the horizon (incorporation of organic matter, peds originated by animals $<5 \%$ ). Traces of current biological activity are possible, organic or organicmineral pellets generated by arthropods or enchytraeids, in any case $<5 \%$ of the soil volume.

Remark: because of observable processes of eluviation or illuviation, the horizon could be defined as msAE (or $\mathrm{msEA}$ ), following its characteristics in common with the mineral E horizon. Sometimes the A horizon shows a laminated and coherent structure because leached humic colloids precipitate and are permeating the mineral component of the horizon, making it massive in appearance. Mechanically induced compaction can also be involved in other circumstances, such as heavy traffic.

Zoogenic and non-zoogenic organic-mineral horizons are compared to each other in Table 1, considering the corresponding FAO (2006) structure, dominant engineering organisms and $\mathrm{pH}$ (water).

\subsection{A horizon and ratio of humic/mineral components}

The ratio of humic and mineral components of the A horizon, even if evaluated by the naked eye, might be a useful field characteristic for better identifying the different diagnostic horizons. Going from left to right across the square diagonally divided in two parts (Fig. 16), coloured in dark grey for humic component (top) and in light grey for mineral component (bottom), the horizons succeed in order from units very rich in humic component (and poor in mineral component) to those very poor in it.

The massive structure has also been detected in very organic and very mineral A horizons and the massive $A$ covers the whole ratio range represented in Figure 16. Biomacro- and biomesostructured $\mathrm{A}$ horizons have a rate of humic component (earthworm-made structures) from $30 \%$ until the entire volume of the horizon. If the rate of humic component is less than $30 \%$, then the 
horizon can be massive, biomicrostructured or single-grain. A single-grain structure has generally been found in horizons very poor in humic component ( $A E, E A)$, less than $10 \%$ of the volume of the horizon. The just cited $A E$ and $E A$ mixed horizons are respectively rather $A$, single-grain or $E$.

If the humic component (microstructured) is more than $50 \%$ of the volume of the horizon, then the probability of it being an $\mathrm{OH}$ horizon instead of an A horizon is very high $(\mathrm{OH}=$ Organic Carbon $>20 \%$ in weight). Humic component is not synonymous of organic matter, especially when droppings are organic-mineral and poor in organic matter. Though not strictly necessary for classifying the humus forms, other important properties of the A horizon can be checked in the field using the Guidelines for Soil Description (FAO, 2006) and/or in the laboratory. The observation and/or measurement of texture, abundance of rock fragments, colour (matrix and mottles), redox potential (Semiterrestrial forms), carbonates (content and forms), organic matter content, porosity and size/abundance of roots is highly recommended.

\subsection{The transition between organic and organic-mineral horizons}

The passage from organic to organic-mineral horizons is an important diagnostic character. In fact, the final issue of a process of litter biodegradation being the complete mineralisation and/or storage of this organic material in an underlying mineral horizon, investigation on the transition from organic to mineral soil "habitats" may give simple but crucial information. Three modalities of passage were individuated, considering the passage from organic to organic-mineral or mineral horizons. In the field we have to estimate the "area of doubt", i.e. the hybrid zone to which it is impossible with naked eyes to assign the name of diagnostic horizon:

- very sharp transition: < $3 \mathrm{~mm}$ (Fig. 17);

- harp transition: $<5 \mathrm{~mm}$;

- gradual transition: $\geq 5 \mathrm{~mm}$ (Fig. 18).

A very sharp transition characterizes Mull or Mor systems. In Mull, the organic horizon is consumed and/or pulled through galleries by earthworms and transformed in a completely different organic-mineral horizon, easy to share from the original organic substrate. In Mor, the organic substrate stays at the top of the soil, the fauna responsible for the integration of organic matter into eventual subjacent mineral horizons being absent. In both cases, the passage from organic to mineral substrate is very sharp.

A gradual transition is typical of Moder system and Mesoamphi humus form. Here enchytraeids and arthropods coming from the organic $\mathrm{OH}$ horizon may defecate in the underlying mineral or organic-mineral horizons, thereby creating a diffused hybrid zone of doubt.

A sharp transition may be found in Macroamphi humus forms, which on one side resemble to Mull humus forms by the dominance of large anecic earthworms and the integration of material from the $\mathrm{O}$ horizon into a biomacrostructured organic-mineral $\mathrm{A}$ horizon, and on the other side resemble to Moder when other animals live and produce organic droppings in both $\mathrm{OH}$ and $\mathrm{A}$ horizons. 


\section{Biological features of biostructured A horizons}

The soil structure is a very important functional soil character (Amossé et al., 2016; Juarez et al., 2013; Piron et al., 2012). Soil has a fractal structure (Perrier et al., 1999): the more you observe it with an increasing magnifying lens, the more the number of structures you are able to detect (Fig. 19). In addition, variations in environmental conditions (climate, vegetation, human activities, etc.) may induce unfavourable niches for large soil earthworms, which are less tolerant and are replaced by smaller, more tolerant species. The result is a reduction in the average size of droppings (Secco et al., 2004; Zanella et al., 2008), switching the soil structure from biomacro to biomeso then to biomicro.

\subsection{Animals, faeces and diagnostic horizons}

A rough recognition key has been created for droppings of the more common soil animals, based on a first version by Galvan et al. $(2005,2006)$. In this field key (Fig. 20) excrements are classified in three categories according to their size and are correlated with the three types of biostructured $\mathrm{A}$ horizons of our humus form classification.

\subsection{Field classification of biostructured $A$ horizons}

An A horizon is generally the result of the activity of soil animals of different species and dimensions. Following pedoclimatic conditions, some species tend to dominate in number and rate of activity. As a consequence, micro- or meso- or macro-structures of the A horizon may be associated with specific soil habitats, which can result in specific humus systems.

The size components of the A horizon may be shared in the field by using two sieves (meshes 4 and $1 \mathrm{~mm}$ ) and collecting the soil that pass even through the second sieve (Fig. 21).

Note: In tropical (French West Indies, French Guiana) and Mediterranean soils (dry variants, as in Sicilia and North Africa), there are biomacrostructured horizons built by other invertebrates such as millipedes (well-known in North America and the Caribbean), tenebrionids (in semi-desert environments), and termites (in Africa). Romell (1935), Eaton (1943), Paulusse and Jeanson (1977), Toyota et al. (2006), Mori et al. (2009), Fujimaki et al. (2010), Francisco and Fontanetti (2015) described Mulls built by millipedes (Cylindroiulus, Parafontaria). All these animals consume organic and mineral matter, as earthworms do, but they form completely different droppings (see Humusica 1, article 8). In drier ecosystems (semi-deserts) termites form lateritic Mull systems (de Barros Machado, 1983). Root systems can be also considered as Mull-forming agents, in particular those of grasses which excrete great amounts of polysaccharides, as in the case of Mollisols in the Great 
Plains of North America and the Pampa. It is true that these organisms are not able to mix litter with mineral matter, as anecic earthworms do, thus they create Amphi rather than Mull systems. It is highly probable that Amphi might be much more common than previously thought, more especially in environments with strong seasonal contrasts such as in Mediterranean and semi-desert biomes, where humus profiles have been often assigned to Xeromoder or to various intergrades between Mull and Moder. Endogeic as well as epigeic earthworms are unable to mix litter with mineral matter by their own, since this is a unique property (ecosystem service?) of anecic earthworms, thus among invertebrates, anecic earthworms seem to be the only true Mull-builders.

\subsection{Comparison of soil structures (FAO, 2006) with biostructures in humus diagnostic horizons}

People accustomed to FAO (2006) references for soil structure may find in Table 2 the corresponding structures to be used for humus system or humus form classification. Many soil structures characterize mineral horizons and have never been found in organic-mineral horizons of common humus systems.

4.4. Diagnostic horizons and main engineering groups of animals in typical and extreme humus forms of each humus system

It is possible to assign to the diagnostic horizons of each terrestrial humus system the main groups of animals involved in their genesis. Thus, endogeic and anecic earthworms generate biomacro- and biomesostructured horizons in Mull and Amphi systems; epigeic earthworms, arthropods (adults and/or larvae) and enchytraeids generate organic horizons in all the other systems; non zoogenic horizons are rather present in Tangel and Mor systems. A more detailed and complete description is furnished in Figure 22.

\section{Horizons mixed by wild mammals}

Mixing of the ground surface by wild mammals leads to burial of the organic $\mathrm{O}$ horizon in the underlying organic-mineral A horizon. This may give rise to difficulties in humus form recognition because organic horizons have disappeared and/or have a variable thickness while A horizons appear to have a heterogeneous structure. This critical situation is most common in areas with a considerable load from wild boars that mix organic with organic-mineral horizons: a horizon that seems decidedly organic to the naked eye becomes organic-mineral after laboratory analysis.

In order to overcome the presence of horizons mixed by wild mammals we propose to use the following additional codes and definitions: 
wild-mammal mixed horizons = organic and organic-mineral horizons mixed by wild mammals. These animals (wild boars, stags, deer, roes, moles, mouse....) partially or completely destroy the natural succession of $\mathrm{OL}, \mathrm{OF}, \mathrm{OH}$ and $\mathrm{A}$ horizons composing a non-disturbed humus profile. After the action of wild mammals, it is then possible to find on one side a mineral component in more superficial $\mathrm{OH}$, OF or OL organic horizons, and on the other side a humic component and recognizable remains of the $\mathrm{O}$ horizon in deeper $\mathrm{A}$ horizons.

$\mathbf{w m O}=$ wild-mammal organic horizons =organic horizons $(\mathrm{OL}, \mathrm{OF}, \mathrm{OH})$ enriched with recognizable aggregates of organic-mineral material (A horizon in pockets); the volume of organic humic component estimated to the naked eye is larger $(>50 \%)$ than the volume of organic-mineral humic component in pockets; wmO mixed horizons are often soft, well aerated horizons. It is relatively easy to distinguish large organic-mineral earthworm casts ( $\mathrm{maA}$ ) in a mass of holorganic humic component; some difficulties overcome when meA or miA are mixed with holorganic material (OH horizon). In these cases it may be helpful to observe that the organic-mineral humic component is often greyish in a black holorganic mass and forms pockets or large aggregates, mineral component being estimated by consistence between fingers or under a magnifying lens.

It is possible to distinguish:

- $w m O L$, when in a wmO the volume of organic-mineral humic component estimated to the naked eye is more than usual for an OL horizon (in a typical OL horizon the humic component should be $<10 \%$ ) but less than $20 \%$ in volume of the mixed horizon (Fig. 23);

- $\quad w m O F$, when in a wmO the volume of organic-mineral humic component estimated to the naked eye is comprised between 20 and $35 \%$ of the volume of the mixed horizon (Figs. 24 and 25);

- $\quad w m O H$, when in a wmO the volume of organic-mineral humic component estimated to the naked eye is more than $35 \%$ (> about $1 / 3$ ) and less than $50 \%$ of the volume of the mixed horizon.

A more precise classification of wmO diagnostic horizons allows individuating the original humus form, using the key of classification with the following approximation: $\mathrm{wmOL}=\mathrm{OL} ; \mathrm{wmOF}=$ $\mathrm{OF}$, or $\mathrm{wmnozOF}=$ nozOF in case of $\mathrm{Mor} ; \mathrm{wmOH}=\mathrm{OH}$. Otherwise the classificatory process has to be terminated at the level of the humus system. Examples of horizon sequences: $\mathrm{wmOH}(<3 \mathrm{~cm})$ and meA $(A \geq O H / 2)=$ Eumesoamphi; $w m O H(\geq 3 \mathrm{~cm})$ and $\mathrm{meA}(\mathrm{A} \geq \mathrm{OH} / 2)=$ Pachyamphi; wmO and nozA = wild mammal Moder or wild mammal Mor; wmOF (nozOF) and $A E=$ wild mammal Mor.

$\mathbf{w m A}=$ wild-mammal $\mathrm{A}$ horizon = organic-mineral horizons $(A)$ mixed by wild mammals with organic horizons ( $\mathrm{OL}, \mathrm{OF}, \mathrm{OH}$ ); in this wild-mammal mixed horizon, the volume of organic-mineral humic component estimated to the naked eye is more than $50 \%$ of the volume of the whole mixed horizon. This means that the organic humic component estimated to the naked eye is less ( $\leq 50 \%)$ than the volume of the mixed horizon; the content of $\mathrm{OC}$ is generally higher than in undisturbed organic-mineral A horizons of the same area. It is possible to distinguish:

- $w m m a A$, when the organic-mineral humic component in admixture with the organic horizon is rather biomacrostructured (Fig. 26);

- wmmeA, when the organic-mineral humic component in admixture with the organic horizon is rather biomesostructured (Fig. 27); 
- $w m m i A$, when the organic-mineral humic component in admixture with the organic horizon is rather biomicrostructured;

- wmnozA, when the organic-mineral humic component in admixture with the organic horizon is non zoogenic.

A more precise classification of wmA diagnostic horizons allows individuating the original humus system, using the key of classification with the following approximation: $w m m a A=m a A$; $w m m e A=m e A ; w m m i A=m i A ; w m n o z A=$ nozA. Otherwise the classificatory process has to be terminated at the level of the humus system. Examples: if wmmaA, the original humus system cannot be Mor, Moder or Tangel; if wmnozA, the original humus system cannot be Mull or Amphi.

\section{Suggested data to collect for a functional humipedon classification}

Example of very simple but complete field entry:

HUMUS SYSTEM:

HUMUS FORM:

Date:

Coordinates:

Locality:

Altitude:

Aspect:

Slope:

Incident radiation or Cover (\%):

Photograph (mandatory, of a complete humipedon: $\mathrm{O}$ and $\mathrm{A}$ horizons)

nOL

Thickness:

Composition (species, \%):

vOL

Thickness:

Other:

zoOF 
Thickness:

Other (roots, animal, fungi activity, etc.):

nozOF

Thickness:

Other:

zoOH

Thickness:

Other (roots, animal, fungi activity, etc.)

nozOH

Thickness:

Other:

Transition between $\mathrm{O}$ and $\mathrm{A}$ horizons:

\section{A}

Type (maA, meA, miA, sgA, msA):

Thickness:

Other (roots, animal activity, porosity, etc.):

\section{AE or EA}

Thickness:

Other (roots, animal, fungi activity, porosity, etc.):

Soil horizon/mineral layer in contact with the humipedon:

Additional observations:

Signs of biological activity:

Mycorrhizae:

Other:

VEGETATION

Photograph (recommended):

Description (not necessarily a specialized survey): 
Structure and species:

\section{SOIL}

Photograph (complete soil profile, recommended):

Name:

Description (not necessarily a specialized survey):

Soil horizons:

Depth (from OF to Lithopedon):

\section{SUBSTRATE}

Name:

$\mathrm{HCl}$ effervescence:

Description (not necessarily a specialized survey):

In the field, it may be useful to have some graphical symbols to our disposal for a rapid report of a humus profile. A series of elemental symbols (triangles or lines for litter; circles for faecal pellets; squares for organic or mineral particles) might be combined for describing different real humus horizons (Figs. 28a and b).

Authors' contributions

A. Zanella, J.F. Ponge, B. Jabiol, G. Sartori, and E. Kolb wrote the text and elaborated the key of classification. Other authors corrected the text, improved the key, participated to researches, field investigations, meetings and fruitful discussions. Not mentioned author of figures and photographs: Augusto Zanella.

\section{References}

Adamchuk, V.I., Hummel, J.W., Morgan, M.T., Upadhyaya, S.K., 2004. On-the-go soil sensors for precision agriculture. Comput. Electron. Agric. 44, 71-91.

Amossé, J., Dózsa-Farkas, K., Boros, G., Rochat, G., Sandoz, G., Fournier, B., Mitchell, E.A.D., Le Bayon, R.C., 2016. Patterns of earthworm, enchytraeid and nematode diversity and community structure in urban soils of different ages. Eur. J. Soil Biol. 73, 46-58.

Callaham Jr., M.A., Richter Jr., D.D., Coleman, D.C., Hofmockel, M., 2006. Long-term land-use effects on soil invertenrate communities in Southern Piedmont soils, USA. Eur. J. Soil Biol. 42, S150S156. 
de Barros Machado, A., 1983. The contribution of termites to the formation of laterites. In: Melphi, A.J., Carvalho, A. (Eds.), Lateritisation Processes. Instituto Astronômico e Geofisico, University of São Paulo, Brazil, pp. 261-270.

Eaton, T.H., 1943. Biology of a mull-forming millipede, Apheloria coriacea (Koch). Am. Midl. Nat. 29, 713-723.

FAO, 2006. Guidelines for Soil Description, $4^{\text {th }}$ edition. FAO, Rome. http://www.fao.org/docrep/019/a0541e/a0541e.pdf (Accessed 30 June 2017).

Florenzano, G., 1972. Elementi Di Microbiologia Del Terreno. REDA, Rome.

Francisco, A., Fontanetti, C.S., 2015. Diplopods and agrochemicals: a review. Water Air Soil Pollut. 226, 53.

Fujimaki, R., Sato, Y., Okai, N., Kaneko, N., 2010. The train millipede (Parafontaria laminata) mediates soil aggregation and $\mathrm{N}$ dynamics in a Japanese larch forest. Geoderma 159, 216-220.

Galvan, P., Scattolin, L., Ponge, J.F., Viola, F., Zanella, A., 2005. Le forme di humus e la pedofauna: interpretazione delle interrelazioni e chiavi di riconoscimento. Sherwood 112, 1-7.

Galvan, P., Solaro, S., Chersich, S., Zanella, A., 2006. Role of soil fauna in the spatial and temporal variation of humus forms: micromorphological investigation on thin sections and stereoscopic observation. Forest@ 3,555-561.

Guillet, B., Rouiller, J., Souchier, B., 1975. Podzolization and clay migration in spodosols of eastern France. Geoderma 14, 223-245.

Hamilton, W.E., Sillman, D.Y., 1989. Influence of earthworm middens on the distribution of soil microarthropods. Biol. Fertil. Soils 8, 279-284.

ISO 10694, 1995. Soil Quality: Determination of Organic and Total Carbon After Dry Combustion (Elementary Analysis). International Organization for Standardization, Geneva.

ISO 10390, 2005. Soil Quality: Determination of pH. International Organization for Standardization, Geneva.

IUSS Working Group WRB, 2015. World Reference Base for Soil Resources 2014, update 2015: International Soil Classification System for Naming Soils and Creating Legends for Soil Maps. FAO, Rome. http://www.fao.org/3/a-i3794e.pdf (Accessed 30 June 2017).

Jongmans, A.G., Pulleman, M.M., Marinissen, J.C.Y., 2001. Soil structure and earthworm activity in a marine silt loam under pasture versus arable land. Biol. Fertil. Soils 33, 279-285.

Juarez, S., Nunan, N., Duday, A.C., Pouteau, V., Schmidt, S., Hapca, S., Falconer, R., Otten, W., Chenu, C., 2013. Effects of different soil structures on the decomposition of native and added organic carbon. Eur. J. Soil Biol. 58, 81-90.

Mori, K., Bernier, N., Kosaki, T., Ponge, J.F., 2009. Tree influence on soil biological activity: what can be inferred from the optical examination of humus profiles? Eur. J. Soil Biol. 45, 290-300. 
Nierop, K.G.J., Buurman, P., 1999. Water-soluble organic matter in incipient podzols: accumulation in B horizons or in fibres? Eur J. Soil Sci. 50, 701-711.

Paulusse, J.H.M., Jeanson, C.Y., 1977. Structuration du sol par les diplopodes: étude expérimentale et microscopique. Ecol. Bull. 25, 484-488.

Peltier, A., Ponge, J.F., Jordana, R., Ariño, A., 2001. Humus forms in Mediterranean scrublands with Aleppo pine. Soil Sci. Soc. Am. J. 65, 884-896.

Perrier, E., Bird, N., Rieu, M., 1999. Generalizing the fractal model of soil structure: the pore-solid fractal approach. Geoderma 88, 137-164.

Piron, D., Pérès, G., Hallaire, V., Cluzeau, D., 2012. Morphological description of soil structure patterns produced by earthworm bioturbation at the profile scale. Eur. J. Soil Biol. 50, 83-90.

Romell, L.G., 1935. An exemple of myriapods as mull formers. Ecology 16, 67-71.

Schoeneberger, P.J., Wysocki, D.A., Benham, E.C., and Soil Survey Staff, 2012. Field Book for Describing and Sampling Soils, Version 3.0. United States Department of Agriculture, Natural Resources Conservation Service, National Soil Survey Center, Lincoln. https://www.nrcs.usda.gov/Internet/FSE DOCUMENTS/nrcs142p2 052523.pdf (Accessed 30 June 2017).

Secco, D., Reinert, D.J., Reichert, J.M., da Ros, C.O., 2004. Produtividade de soja e propriedades físicas de um Latossolo submetido a sistemas de manejo e compactação. Rev. Bras. Ciência Solo $28,797-804$.

Soil Survey Staff, 2014. Keys to Soil Taxonomy by Soil Survey Staff, 12th edition. United States Department of Agriculture, Natural Resources Conservation Service, Washington. https://www.nrcs.usda.gov/wps/portal/nrcs/detail/soils/survey/class/taxonomy/?cid=nrcs14 2p2 053580 (Accessed 30 June 2017).

Toyota, A., Kaneko, N., Ito, M.T., 2006. Soil ecosystem engineering by the train millipede Parafontaria laminata in a Japanese larch forest. Soil Biol. Biochem. 38, 1840-1850.

Zanella, A., Secco, R., Tarasconi, L., Jabiol, B., Viola, F., 2008. Struttura degli orizzonti diagnostici e classificazione delle forme di humus. Forest@ 5, 68-81. 


\section{Figure captions}

Fig. 1. Vocabulary and dynamic formation of a general terrestrial humipedon. Aboveand belowground processes are similar. On one side "decomposition" or "weathering" (from complex structures to their unit components) from leaves to molecules, from minerals to elements; on the other side "composition" (from atoms or molecules to new structures) from mineral elements, organic molecules and water to biological structures (trees, animals...), from minerals to new clay, humic component, soil sub-units (peds).

Fig. 2. Recognizable remains and humic component: a) Recognizable remains, pieces of leaves and twigs from an $\mathrm{OL}$ horizon; b) humic component from an $\mathrm{OH}$ horizon, made of small millimetre spherical droppings of animals which consumed and transformed plant remains; c) Meso-, macro- and micro-structured humic component from an A horizon.

Fig. 3. Non-zoogenically transformed material: a) Dry or cold climate, acidity, unpalatability of the substrate may prevent faunal activity. Here a humipedon in an artificial stand of Pinus radiata in substitution of a natural Quercus ilex forest. The decomposition of the organic substrate is essentially due to fungal attack. Note that humic component is absent; b) Dry or cold climate, acidity, unpalatability of the substrate may prevent faunal activity. Here a humipedon in an oak forest on sandy acid substrate and with introduced Scots pine. The decomposition of the organic substrate is essentially due to fungal attack.

Fig. 4. Organic horizons components: a) Humic component and recognizable remains in the main organic horizons. By moving a narrow vertical window across the squared graph, humic component and recognizable remains appear in their respective importance (percentage) in the composition of an observed horizon. Among fresh or still not degraded litter (OL horizon), the volume of humic component will be negligible $(<10 \%)$ against recognizable remains; in a well-humified organic layer ( $\mathrm{OH}$ horizon), the volume of humic component dominates $(>70 \%)$ that of recognizable remains; the OF horizon corresponds to intermediate situations; $b$ ) Zoogenically Transformed Material and Non-Zoogenically Transformed Material in zoogenic and non-zoogenic OF horizon types.

Fig. 5. nOL horizon: a) nOL from an oak-hornbeam forest, on neutral substrate under temperate climate; b) $\mathrm{nOL}$ in a sample square $(50 \times 50 \mathrm{~cm})$ of a Quercus pubescens forest with Carex humilis on a dry calcareous soil; c) $\mathrm{nOL}$ in a tropical forest. Even if a very low soil pH is observed $(\leq 4.5)$, temperature and moisture compensate the acidity and a very active Mull humus system often occurs in equatorial areas. The equatorial Mull shows a large amount of living roots of trees at its surface (photograph M. De Nobili); d) nOL in a Pinus sy/vestris forest on acid substrate under temperate climate, in mosaic with moss cushions. With a volume of dead moss organs (leaves and stems) of more than $90 \%$ in the cumulated diagnostic horizons, the humipedon is considered as a Bryo system, i. e. a humus system prominently influenced by the mosses. This is the case in the parts of the surface covered by green cushions of Leucobryum glaucum while poorly covered with pine needles; e) nOL from a Quercus ilex forest on calcareous substrate under Mediterranean climate. (For interpretation of the references to colour in this figure legend, the reader is referred to the web version of this article). 
Fig. 6. vOL horizon: a) Leaves of Carpinus betulus stuck together by fungal hyphae. vOL is made of leaves which have been eaten (skeletonized) by enchytraeids. These little annelids consume the more palatable parts of the leaves, letting untouched petioles and nerves; $b$ ) Leaves of Castanea sativa sticked in a mat by fungal hyphae. A fungal carpophore (mushroom) is also present; c) Leaves of Quercus robur stuck together by fungal hyphae; d) vOL in an oak-beech forest, with some chestnut trees (nOL has been swept away). Many leaves are still entire or in large pieces. The dominant colour of $\mathrm{VOL}$ is clear brown or beige or white; e) VOL in an oakbeech forest ( $\mathrm{nOL}$ has been swept away). Generally vOL leaves form pockets, 2-4 superposed leaves being often stuck together by fungal hyphae.

Fig. 7. zoOF horizon: a) zoOF from a beech forest, on neutral substrate, under temperate climate. A lot of brown granular animal faeces (humic component) are visible among fragments of leaves. While plant remains continue to be transformed, the share of animal faeces increases, stemming in the formation of the $\mathrm{OH}$ horizon except when carried to the $\mathrm{A}$ horizon by burrowing animals; b) zoOF from a beech forest, on acid substrate, under temperate climate. The matrix of this horizon is composed of fine $(<1 \mathrm{~mm})$ brown granular droppings as humic component; c) same beech forest, zoOF horizon less active and more compact, enriched in mineral grains; d) zoOF from an holm oak forest, on calcareous substrate, under Mediterranean climate. A lot of arthropod droppings are visible among the leaves.

Fig. 8. nozOF horizon: a) nozOF, under Juniperus sabinae in a Mediterranean maquis. No faunal activity, but presence of white mycelia; b) nozOF, under $\mathrm{nOL}$ and $\mathrm{VOL}$, in an artificial plantation of Pinus radiata, under Mediterranean climate. Some signs of faunal activity (droppings) are visible at the same depth level of white mycelia, indicating that this horizon is evolving towards a zoogenic horizon, thereby unlocking the fungal-only degradation system; c) nozOF, in a subalpine spruce forest, first top $3-4 \mathrm{~cm}$ of the humipedon. Faunal activity is present, together with patches of white hyphae, and the accumulation of faunal droppings form a thick zoogenic $\mathrm{OH}$ horizon underneath. Fungal development is the main food source for soil animals belonging to the decomposer system while spruce needles are discarded until they have reached an advanced stage of fungal decay.

Fig. 9. zoOH and szoOH horizon: a) zoOH in a Mediterranean forest of Quercus ilex. Composition: humic component (fine granular faeces) and roots; b) $\mathrm{zoOH}$ in a subalpine spruce forest. It corresponds to the brown layer in the middle of the sample of the humipedon, which is made of OL $(1-2 \mathrm{~cm}), \mathrm{OF}(2-3 \mathrm{~cm}), \mathrm{zOOH}(8-9 \mathrm{~cm})$, with a gradual passage to $\mathrm{miA}(2 \mathrm{~cm})$, the whole lying on a clearer $\mathrm{B}$ horizon. $90 \%$ of $\mathrm{zoOH}$ is made of granular humic component (faunal droppings); c) zoOH from a beech forest, on acid substrate, under temperate climate. A fine granular matrix, made of enchytraeid and arthropod droppings, composes $90 \%$ of the horizon. Note that a few mineral grains are visible as white spots; d) zoOH from an Alpine beech forest, under temperate climate. In this ecosystem, enchytraeids (little white transparent microannelid worms) play a dominant role in litter biodegradation. The passage between $\mathrm{OH}$ and $\mathrm{A}$ is very gradual and it is often difficult in the field to mark the limit between these horizons of a Biomesoamphi; e) szoOH in an oak-beech forest with sparse planted Scots pines in Fontainebleau forest (France). In this ecosystem, litter biodegradation can be periodically arrested by summer drought. A relatively thick $(3-5 \mathrm{~cm}) \mathrm{szoOH}$ horizon takes place on a podzolic mineral grey $E$ horizon at the top of a sandy draining substrate. 
Fig. 10. Zoogenic and non-zoogenic organic-mineral horizons. Note that the distinction between single-grain and massive structure depend mainly on the dominant textural class in the soil skeleton (sand for single-grain, silt for massive).

Fig. 11. Biomacrostructured A: a) Sample of biomacrostructured A horizon on a hand palm with an anecic earthworm (Lumbricus terrestris, red pointed head, clear rounded and flattened tail); b) Biomacrostructured A horizon from a European temperate broad-leaved forest. It mostly results from the activity of anecic earthworms; c) Biomacrostructured A horizon in an oakhornbeam forest. Large earthworm aggregates of are composed of micro-units resulting from secondary attack by enchytraeids and micro-arthropods; d) Biomacrostructured A horizon from an Alpine meadow. It corresponds to a Mull humus system during the few decades of the regeneration phase of a spruce forest. The complete dynamic cycle of this forest lasts a few centuries and its dominant humus system is Moder; e) Termite nest surfacing in a grazed field in South Africa (sub-tropical highland, elevation $1522 \mathrm{~m}$, Pretoria region). All around the nest the A horizon shows a biomacrostructure very similar to the one made by anecic or endogeic earthworms (see Fig. 11f), despite the visible absence of earthworms in the area; f) Surface view of a biomacrostructure originating from the join activity of termites and other arthropods (insect larvae, millipedes) in the earth excavated by moles in a grazed field in South Africa (sub-tropical highland, Pretoria). No signs of earthworm activity in the area, even if their presence cannot be excluded; g) Biomacrostructured $A$ horizon in a sub-tropical highland (South Africa). This A horizon shows a brown colour and deepens to $20-25 \mathrm{~cm}$ in the soil, creating pockets irregular in size. Grass roots are also involved in the construction of the structure. Red $A B(5 \mathrm{~cm}$, under $A)$ and $B$ horizons, generated in a Mg-rich dolomite, characterize the main part of this soil profile; $h$ ) Poorly zoogenic massive $A$ horizon under semi-arid climate in South Africa (100 km south of Bloemfontein), in a corn crop field. Non zoogenic aggregates are angular and display a wide range of sizes. Termites and other arthropods (millipedes, insect larvae) were checked in the area, feeding on mulch or manure distributed here and there by the farmer. Reducing the stress to soil faunal activity imposed by agriculture (minimum tillage or no-tillage, decreased use of herbicides/pesticides, etc.) and feeding the soil with compost or mulch could well increase the biodiversity of this soil, getting it back slowly (in such a dry sub-tropical climate) to the original biomeso-or biomacrostructured soil. (For interpretation of the references to colour in this figure legend, the reader is referred to the web version of this article).

Fig. 12. Biomesostructured $A$ horizon: a) Biomesostructured $A$ horizon in an oak Mediterranean forest. Less than $1 / 3$ of the volume is occupied by large earthworm aggregates; $b$ ) Biomesostructured A horizon made by tipulid (fly) larvae in a Mediterranean oak forest. The passage between $\mathrm{OH}$ and $\mathrm{A}$ horizons is gradual; a laboratory analysis is often necessary for sharing $\mathrm{A}$ and $\mathrm{OH}(\mathrm{OC}>20 \%$ in $\mathrm{OH})$; c) Biomesostructured $A$ horizon from an Alpine beech forest. Large enchytraeids (white transparent microannelid worms) play a dominant role in building the structure of this horizon in some Amphi humus systems.

Fig. 13. Biomicrostructured A: a) Biomicrostructured A in a Mediterranean Moder, in a Quercus suber forest. Granular consistence, admixture of organic (dark, black), organic-mineral (grey, beige) and mineral (clear, white) grains; b) Biomicrostructured A in a Moder, in a Fagus sy/vatica forest. Very fine organic, organic-mineral and mineral (white) grains. 
Fig. 14. Single-grain $A, \operatorname{sgA}$ (thin grey horizon $<1 \mathrm{~cm}$ ) under a nozOH in a Mor, passing to a podzolic $E$, in a beech-oak forest with Pinus sylvestris, on acid sandy substrate under temperate climate.

Fig. 15. Massive $A$, msA (thin dark grey horizon between a brown $\mathrm{OH}$ and a dark grey $A E$ then light grey $E$ horizon) in a Dysmoder, in a beech-oak forest under temperate climate, on acid sandy substrate. Both msA and AE break like a piece of sugar.

Fig. 16. Range of the ratio of humic component $(\mathrm{HC})$ to mineral component $(\mathrm{MC})$ in the different $A$ horizons, distinguished by the naked eye or with the help of a 5-10x magnifying hand lens. At this scale, mineral grains included in animal droppings are considered as belonging to humic component; only free or very weakly bound grains are considered as mineral component. Biomacro- and biomesostructures differ by the mean size of the peds but not by the $\mathrm{HC} / \mathrm{MC}$ ratio, which is generally very high (often $100 \%$ ). On the right side, the biomicrostructured $A$ becomes single-grain $A$ when $\mathrm{MC}$ rises to more than $90 \%$ of the horizon volume; on the left side, the biomicrostructured $\mathrm{A}$ becomes an $\mathrm{OH}$ horizon when $\mathrm{MC}$ decreases until less than $50 \%$ of the horizon volume. The massive structure is independent of the HC/MC ratio.

Fig. 17. Very sharp transition between $\mathrm{OH}$ and $\mathrm{E}$ horizons in a Mor system. A sharp line separates brown-red organic layers from clear mineral ones.

Fig. 18. Gradual transition between $\mathrm{OH}$ and miA horizons in a Moder system. In this case the $\mathrm{OH}$ horizon is made of an accumulation of black organic enchytraeid faeces, the miA horizon is dark grey and composed of organic-mineral enchytraeid faeces and a few sand grains. It is impossible to share with a thin line organic and organic-mineral layers, the organic black layer is evident at the top, the grey black organic-mineral is present at the bottom; in the middle a large belt $(>1 \mathrm{~cm})$ is progressively joining the two horizons.

Fig. 19. The fractal nature of soil structure. Pictures at different scales were found online and were reassembled. In background the photograph of a Fannia fly larva found in a Moder in the Fontainebleau forest. The size of this small animal (3-4 $\mathrm{mm}$ ) may be compared to one of the largest aggregates $(1-2 \mathrm{~mm})$ placed in the upper left corner. The figure illustrates the complexity of the soil world. The human mind is rather accustomed to apprehend objects at a "visible to naked eye" scale. The functional value of structures smaller than $1 / 10 \mathrm{~mm}$ is thus often overlooked. We breath, drink and eat a lot of bacteria, we are covered by billions of microorganisms but we never think to them unless we are ill. The same happens when we look at the soil. Making a hole, we move billions of microorganisms (Florenzano, 1972), but we do not think to them and generally classify the soil without considering this immense natural force (A. Zanella, A. Squartini).

Fig. 20. Field classification of droppings of most common groups of pedofauna (modified from Galvan et al., 2005). Droppings are divided into three categories, named micro ( $\leq 1 \mathrm{~mm})$, meso (between 1 and $4 \mathrm{~mm}$ ) and macro ( $>4 \mathrm{~mm}$ ), corresponding to the abovementioned zoogenic A horizons miA, meA and maA (A. Zanella, J.F. Ponge, P. Galvan).

Fig. 21. Different groups of soil fauna and structure of the A horizon. On the picture, an $A$ biomacrostructured horizon has been sieved and the three components of different mean size have been disposed on the cover of a Munsell's manual (used for the estimation of the 
soil colour in a previous step). The proportion of aggregates is estimated by naked eye or with the help of a little field balance. In the case of a biomacrostructured $A$, the estimation is based on the volume of biomacropeds, which has to be larger than $1 / 3$ of the volume of the horizon (case in picture). When biomicropeds largely dominate the sample (volume $>2 / 3$ ) the horizon is biomicrostructured. Doubtful estimates made by the naked eye generally fall in biomesostructured horizons after measurement with a balance.

Fig. 22. Terrestrial diagnostic horizons and engineering pedofauna. For each humus system we reported a central typical form (eu) and a diverging form (less active form in all systems but Mor). The less active Mor form is the typical one (eu), the divergent being a little more active in transition towards a Moder system (humi). Legend: eu=eu (central); pac =pachy (with thick organic horizons), dys = dys (more acid), hu = humo (with zoogenic organic horizons). (A. Zanella, B. Jabiol, J.F. Ponge).

Figs. 23-27. Wild-mammal mixed horizons. (23) wmOL, from a Mediterranean holm oak forest. Exogenous humic component (organic-mineral aggregates) are less than $1 / 4$ of the volume of the horizon; OL components (entire oak leaves) largely dominate in volume. (24) A thick (> 10 $\mathrm{cm}$ ) wmOF under an nOL horizon, in an oak forest under temperate climate. In the mixed horizon, the humic component occupies about half the horizon volume. (25) wmOF, from an oak forest under temperate climate. In the mixed horizon, the humic component occupies about half the horizon volume. (26) wmmaA, in a Mediterranean holm oak forest. Dominant soil aggregates have dimensions $>4 \mathrm{~mm}$. (27) wmmeA, in a Mediterranean holm oak forest. Dominant soil aggregates have dimensions between 1 and $4 \mathrm{~mm}$.

Fig. 28. top) Graphical symbols for field survey; bottom) Component symbols are combined in horizon symbols. 
Table 1

Classification of organic-mineral horizons. Zoogenic A horizons are divided into biomacro, biomeso or biomicrostructured horizons; non-zoogenic A horizons are divided into single grain or massive unstructured horizons.

\begin{tabular}{|c|c|c|c|}
\hline Zoogenic A horizons & Structure (FAO, 2006) & Dominant engineering organisms & $\mathrm{pH}$ (water) \\
\hline $\begin{array}{l}\text { maA: Biomacrostructured } \\
\qquad \mathrm{A}=\text { Aneci-endovermic } \mathrm{A}\end{array}$ & $\begin{array}{l}\text { Never lack of structure } \\
\text { Grade: moderate or strong } \\
\text { Shape: granular and/or subangular } \\
\text { blocky } \\
\text { Size of dominant (in volume) peds: } \\
\text { o }>4 \mathrm{~mm}\end{array}$ & $\begin{array}{l}\text { The whole horizon is made of more or less aged anecic and } \\
\text { endogeic earthworm droppings. Roots dominate in particular } \\
\text { circumstances }\end{array}$ & $\begin{array}{l}\text { More than } 5 \text { (rare exceptions } \\
\text { lower but near } 5 \text { are } \\
\text { possible) }\end{array}$ \\
\hline $\begin{array}{l}\text { meA: } \text { Biomesostructured A = Endo- } \\
\text { epivermic A }\end{array}$ & $\begin{array}{l}\text { Never lack of structure } \\
\text { Grade: moderate or strong (rarely } \\
\text { weak) } \\
\text { Shape: granular and/or subangular } \\
\text { blocky } \\
\text { Size of dominant (in volume) peds: } \\
1<0 \leq 4 \mathrm{~mm}\end{array}$ & $\begin{array}{l}\text { The largest part of the horizon is made of epigeic and small } \\
\text { endogeic earthworm, enchytraeid and arthropod droppings. } \\
\text { Roots dominate in particular circumstances }\end{array}$ & $\begin{array}{l}\text { A large range from acid to } \\
\text { basic values has been } \\
\text { observed }\end{array}$ \\
\hline $\begin{array}{l}\text { miA: Biomicrostructured A = Enchy- } \\
\quad \text { arthropodic A }\end{array}$ & $\begin{array}{l}\text { Grade: moderate, strong } \\
\text { Shape: granular } \\
\text { Size of dominant (in volume) peds: } \\
\text { o } \leq 1 \mathrm{~mm} \text {; peds }>4 \mathrm{~mm} \text { never } \\
\text { present }\end{array}$ & $\begin{array}{l}\text { Enchytraeids (potworms) and microarthropods (tiny larval } \\
\text { stages of insects, mites, springtails...). Roots dominate in } \\
\text { particular circumstances }\end{array}$ & $\begin{array}{l}\text { Less than } 5 \text { (rare exceptions } \\
\text { higher but near } 5 \text { are } \\
\text { possible) }\end{array}$ \\
\hline sgA: Single grain A & $\begin{array}{l}\text { Single grain. Unbound loose } \\
\text { consistence. } \\
\text { Presence of clean (= uncoated) } \\
\text { mineral grains }\end{array}$ & $\begin{array}{l}\text { Observable process of eluviation or podzolisation Fine organic } \\
\text { particles and/or biogenic peds }<10 \% \text { in volume }\end{array}$ & $\begin{array}{l}\text { Less than } 5 \text { (rare exceptions } \\
\text { lower but near } 5 \text { are } \\
\text { possible) }\end{array}$ \\
\hline msA: Massive A & $\begin{array}{l}\text { Massive. } \\
\text { If dry: the one-piece soil breaks up } \\
\text { into finer artificial units; } \\
\text { If moist: the one-piece soil can be } \\
\text { transformed into tender, plastic, non- } \\
\text { elastic matter }\end{array}$ & $\begin{array}{l}\text { Cohesion forces among soil components appear equally } \\
\text { distributed in the horizon, as they depend mostly on physical or } \\
\text { chemical condition rather than biological aggregation }\end{array}$ & $\begin{array}{l}\text { Less than } 5 \text { (exceptions are } \\
\text { possible) }\end{array}$ \\
\hline
\end{tabular}


Table 2

Type of structure in soil horizons using a FAO (2006) reference and corresponding structures presented in this manual.

\begin{tabular}{|c|c|c|}
\hline Type of Soil Structure & Size & corresponding structure used for humus systems classification \\
\hline SG (Single Grain) & & single grain \\
\hline PL (Platy) & & probably not of biological origin: compaction by heavy traffic or freeze-thaw cycles? \\
\hline PR (Prismatic), PS (Subangular prismatic) & & not found \\
\hline CO (Columnar) & & not found \\
\hline BL AP (Parallelepiped Angular Blocky) & & not found \\
\hline BL AW (Angular Blocky Wedge-shaped) & & not found \\
\hline BL SB(Subangular Blocky) & $\begin{array}{l}\text { Very fine }(<5 \mathrm{~mm}) \\
\text { Fine }(5-10 \mathrm{~mm})\end{array}$ & $\begin{array}{l}\text { biomacro }(4 \mathrm{~mm} \text { ) or biomeso ( }>1 \text { et }<4 \mathrm{~mm} \text { ), aged earthworm/enchytraeid feces } \\
\text { biomacro }(5 \mathrm{~mm} \text { ) probably aged earthworm feces }\end{array}$ \\
\hline BL SN (Nutty Subangular Blocky) & & not found \\
\hline WE (Wedge-shaped) & & not found \\
\hline CR (Crumbly) & Very fine $(<5 \mathrm{~mm})$ & biomacro $(4 \mathrm{~mm})$ \\
\hline & Fine $(5-10 \mathrm{~mm})$ & biomacro $(5 \mathrm{~mm})$ \\
\hline GR (Granular) & Very fine $(<1 \mathrm{~mm})$ & biomicro $(<1 \mathrm{~mm})$ \\
\hline & Fine $(1-2 \mathrm{~mm})$ & biomeso (1-2 mm) \\
\hline & Medium $(2-5 \mathrm{~mm})$ & biomacro $(4-5 \mathrm{~mm})$ \\
\hline CL (Clody) & Very fine $(<5 \mathrm{~mm})$ & structureless massive material (in agricultural fields) \\
\hline & Fine $(5-10 \mathrm{~mm})$ & structureless massive material (in agricultural fields) \\
\hline WC (Worm casts) & & biomacro or biomeso \\
\hline RS (Rock structure), SS (Stratified structure) & & not found \\
\hline BL SN (Nutty subangular blocky) & & not found \\
\hline
\end{tabular}




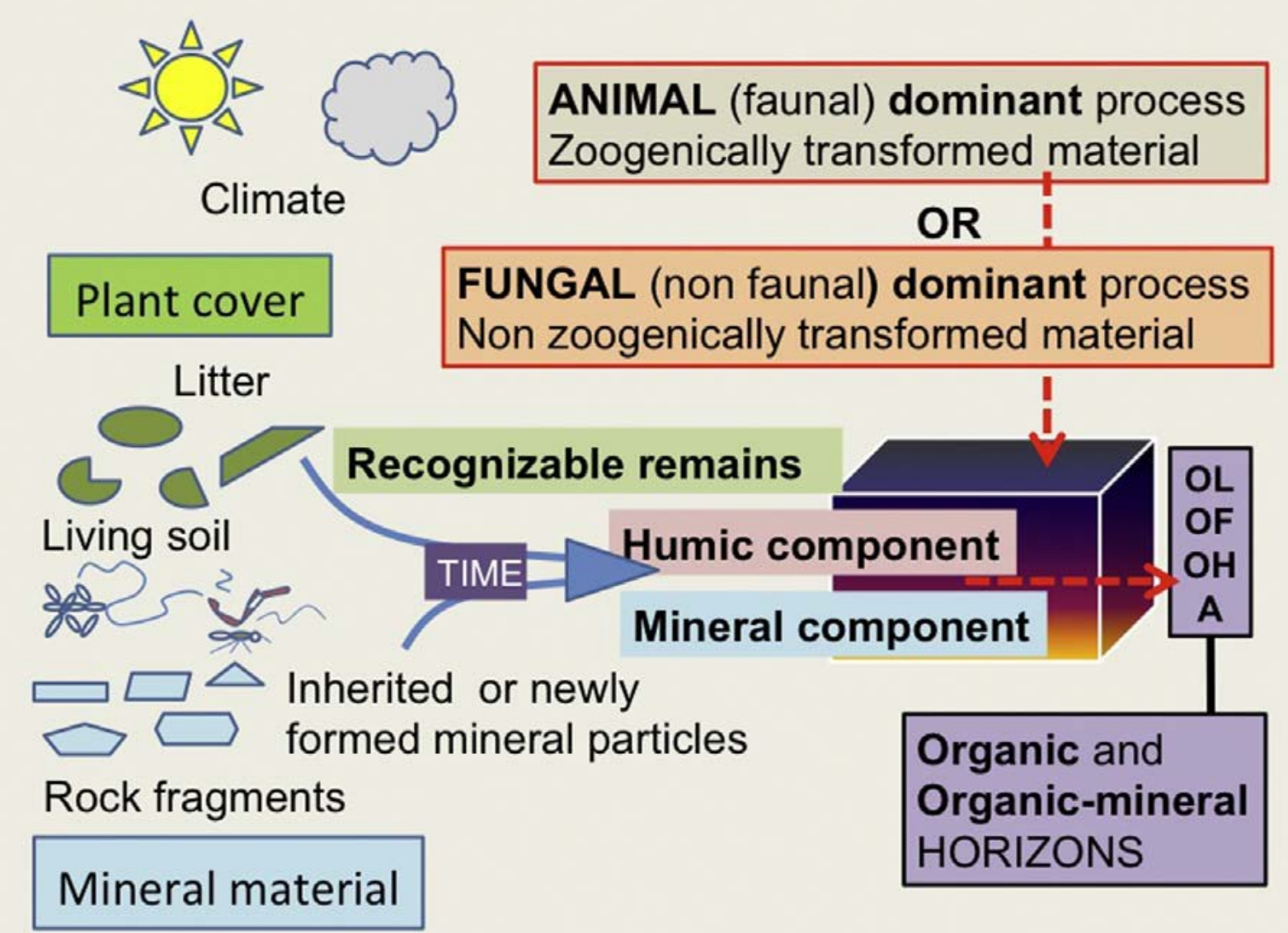

Fig. 1 
a)

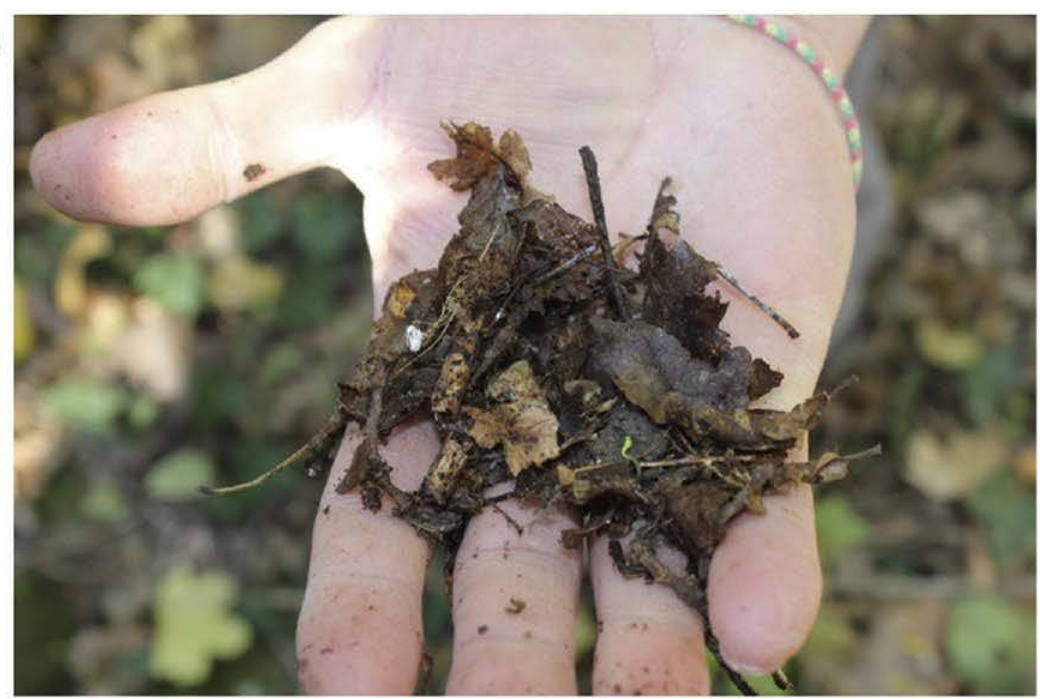

b)

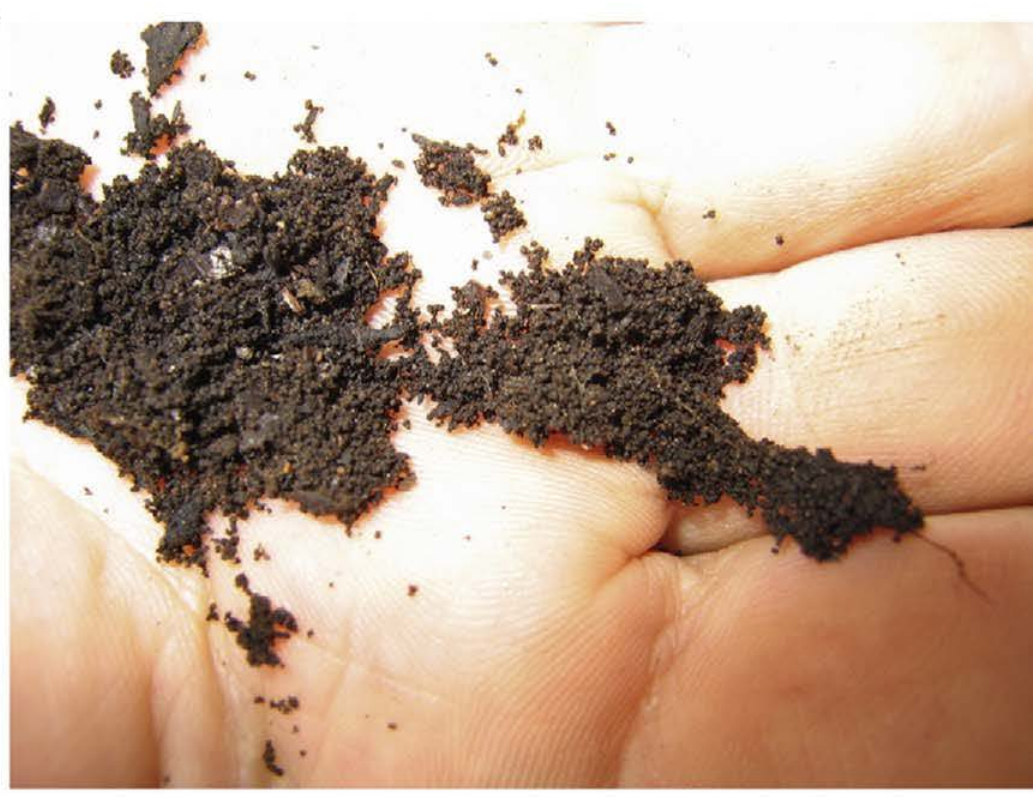

c)

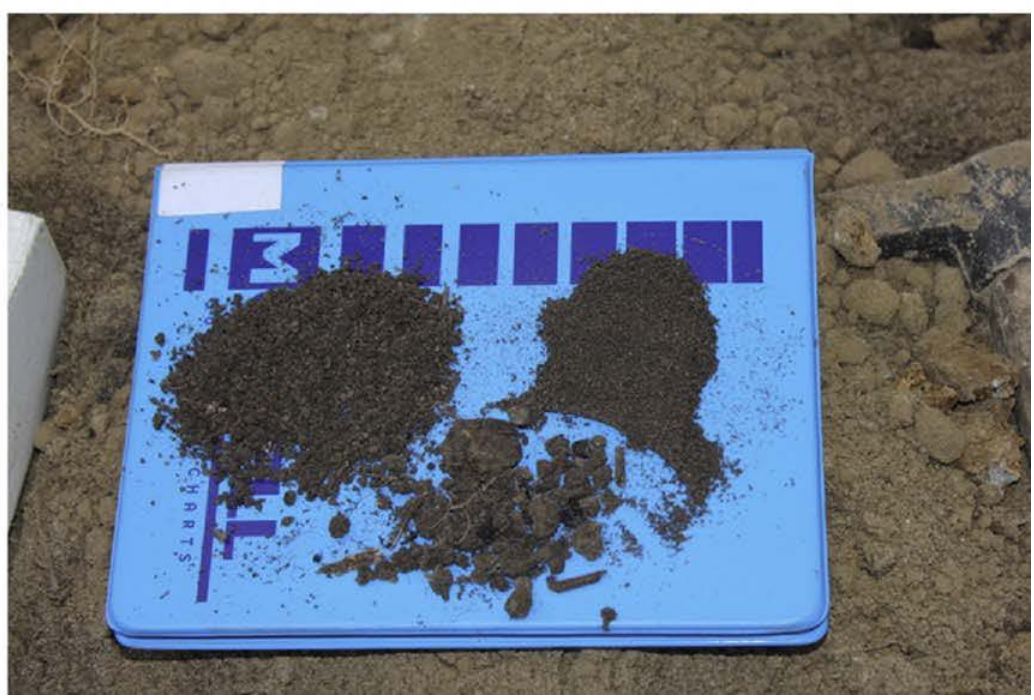

Fig. 2 
a)

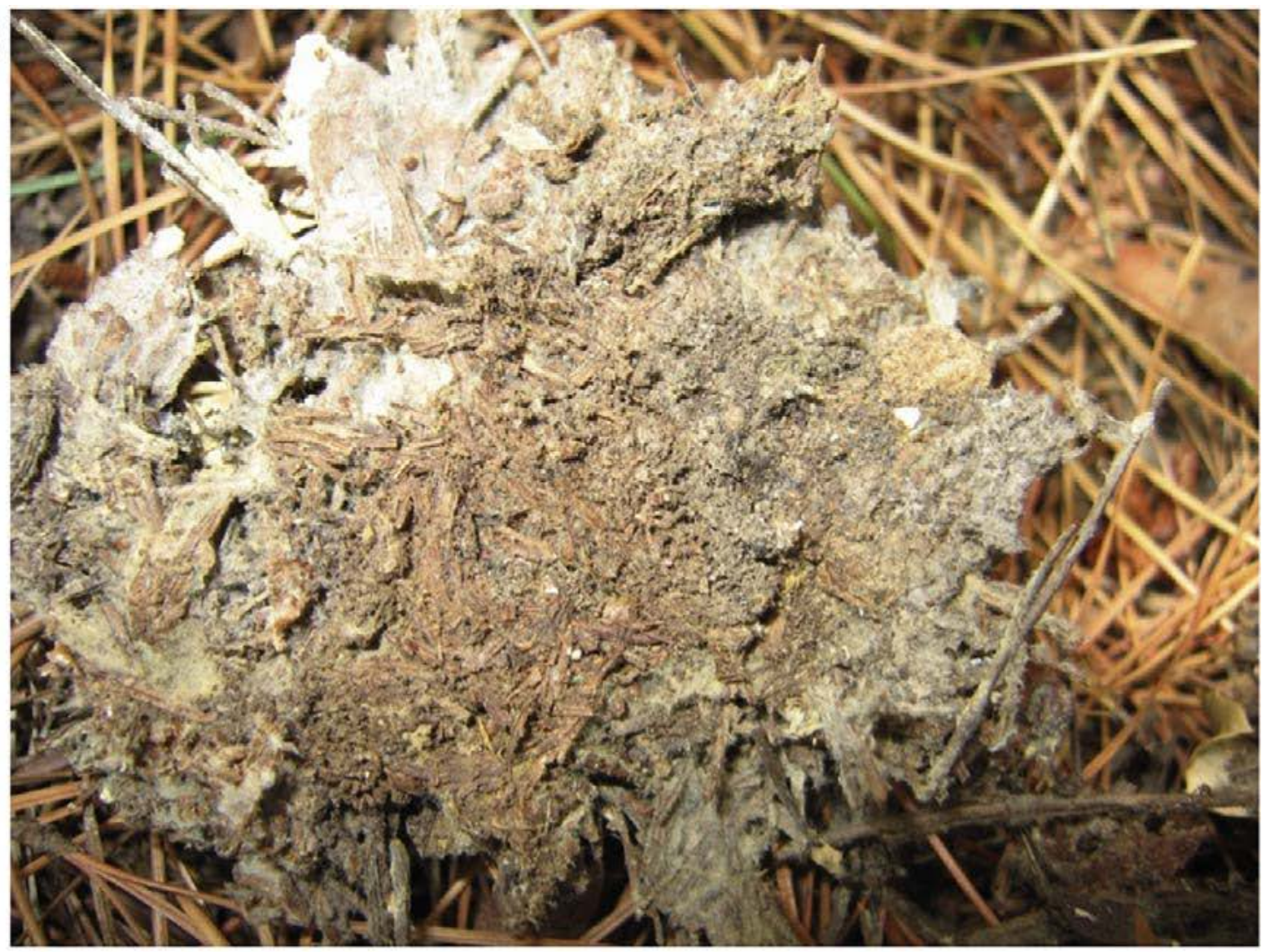

b)

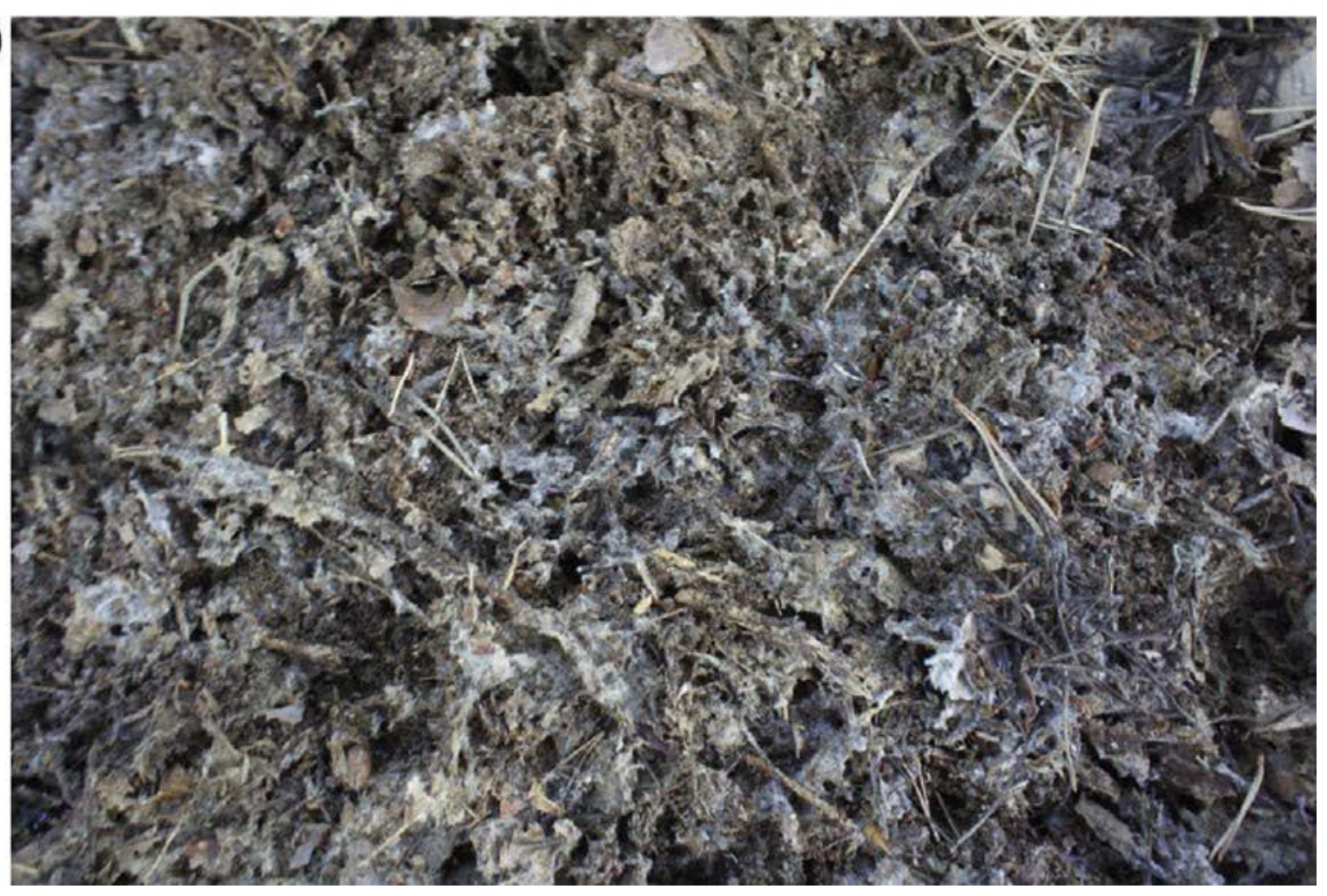

Fig. 3 
a) $\mathrm{OL}, \mathrm{OF}, \mathrm{OH}$

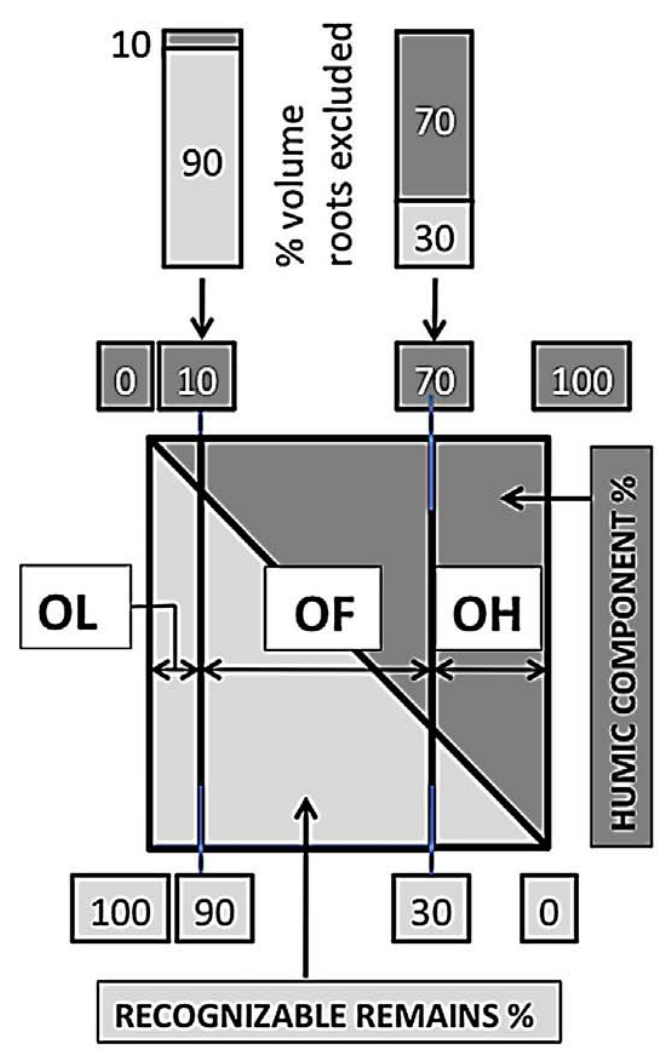

b) zoOF, nozOF

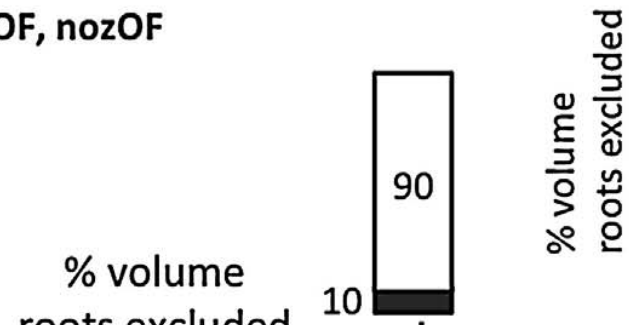
roots excluded
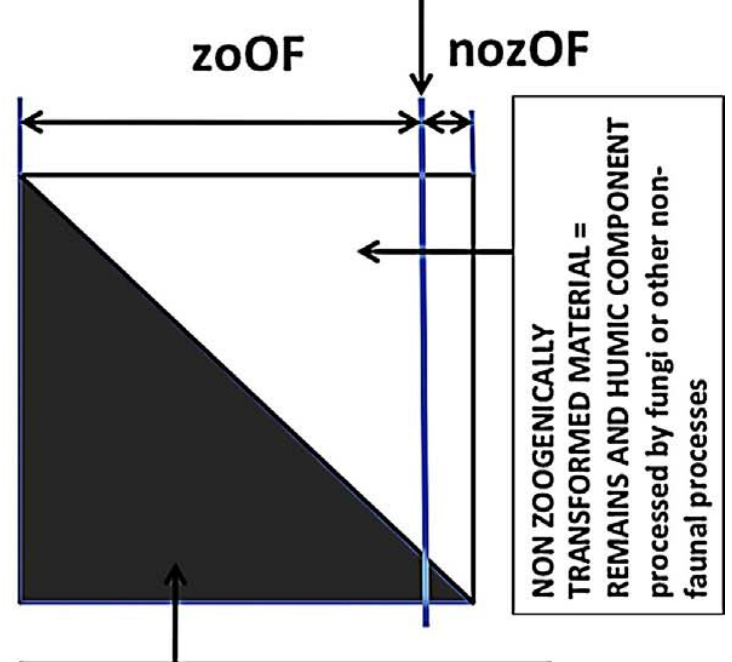

ZOOGENICALLY TRANSFORMED

MATERIAL $=$ RECOGNIZABLE

REMAINS AND HUMIC COMPONENT

processed by animals

Fig. 4 

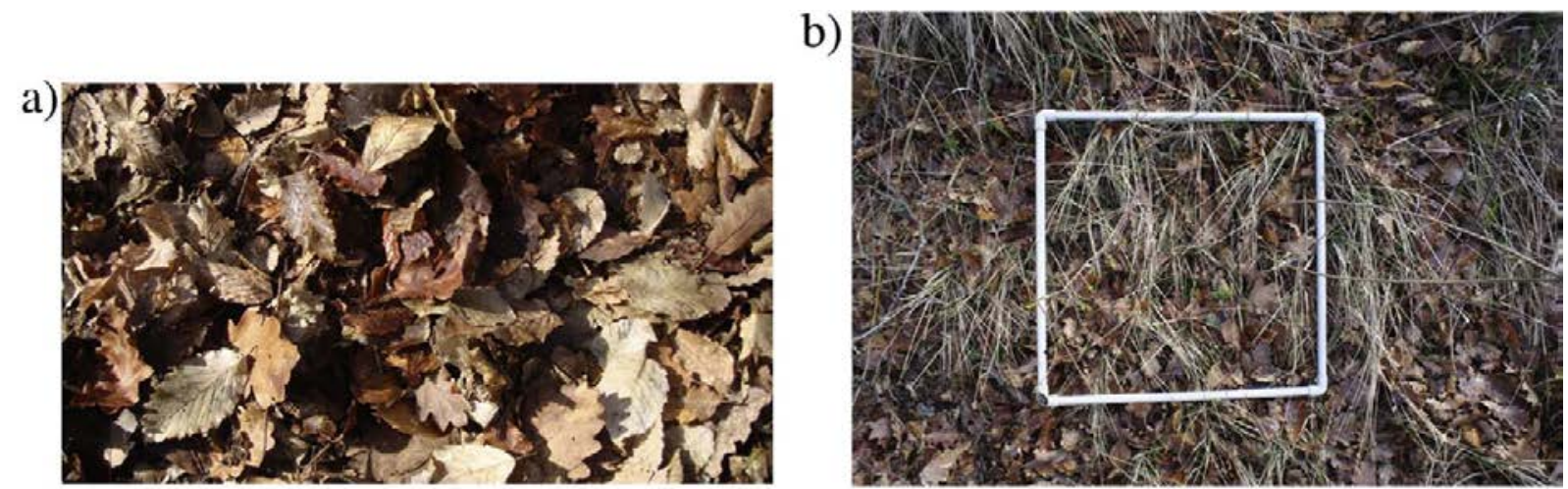

c)

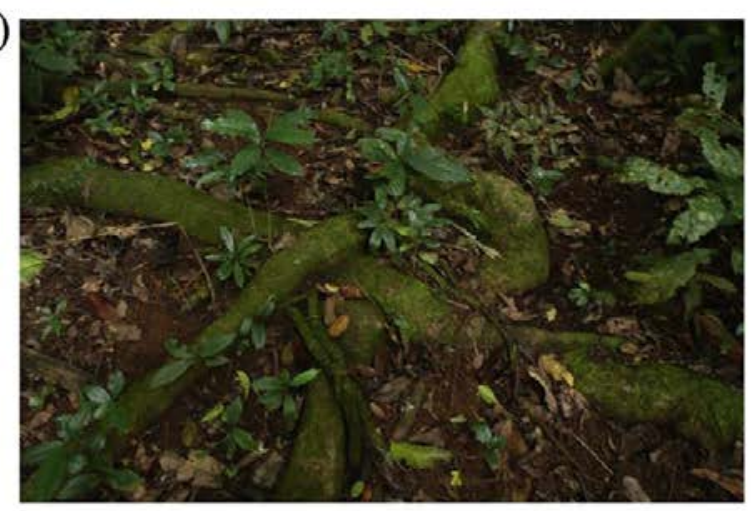

e)

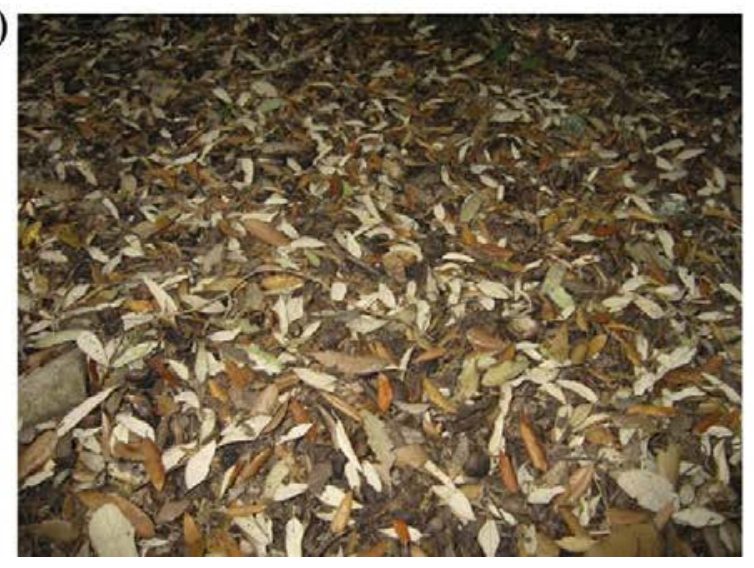

d)

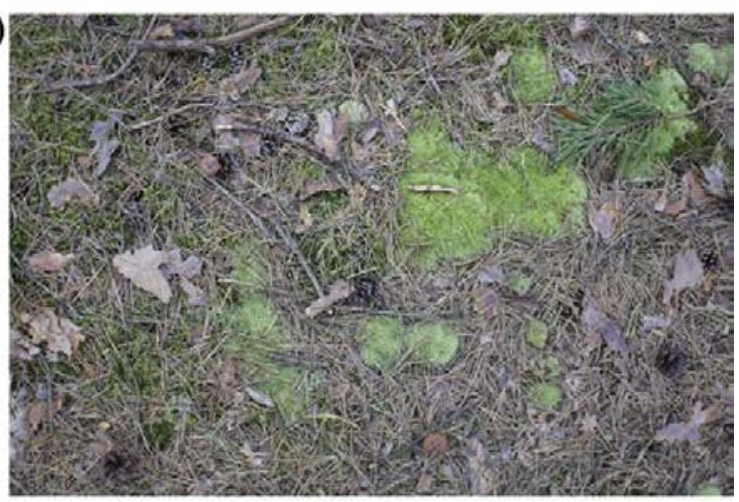

Fig. 5 
a)

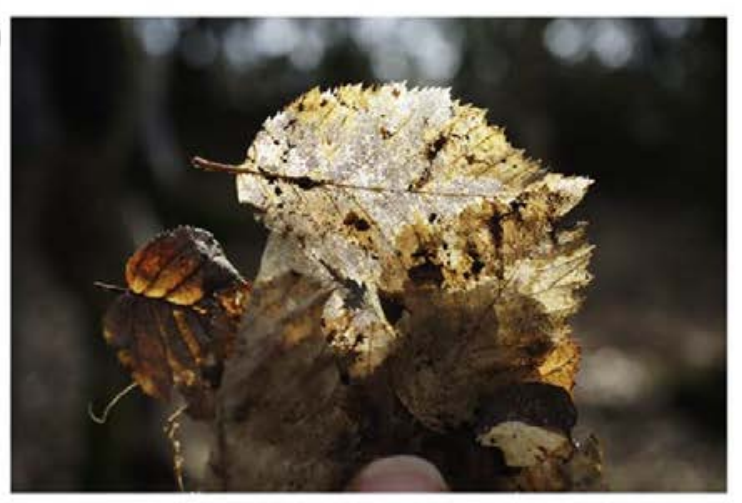

c)

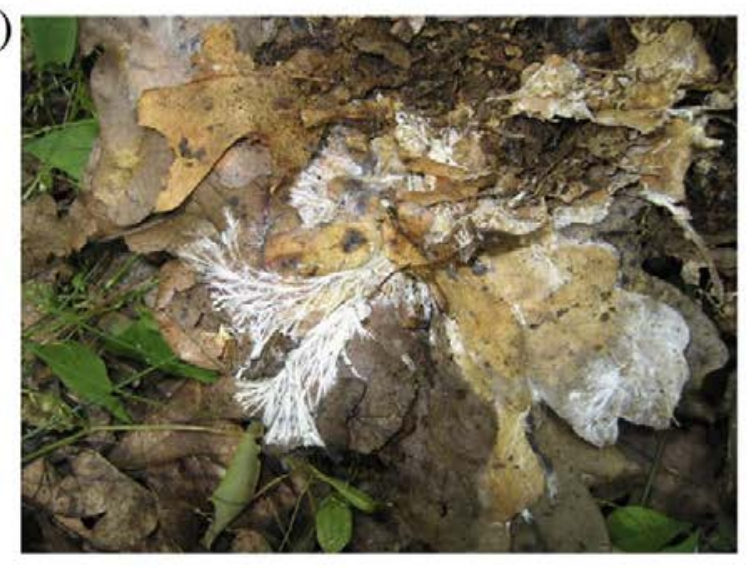

e)

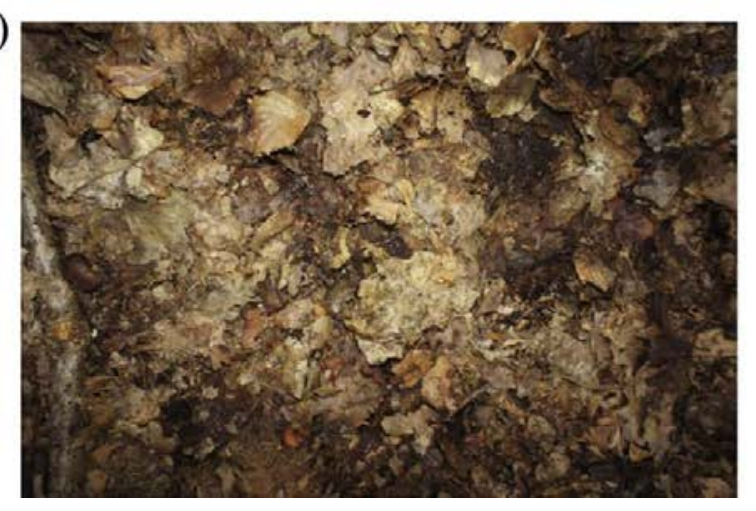

Fig. 6

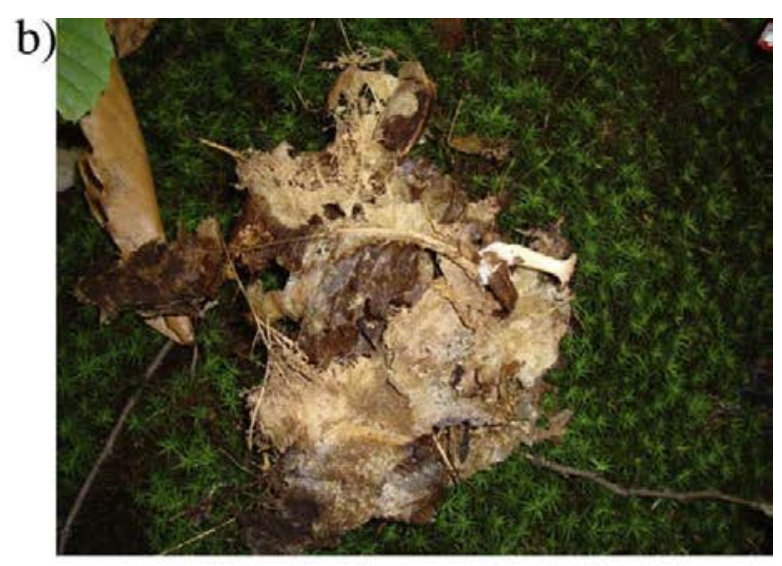

d)

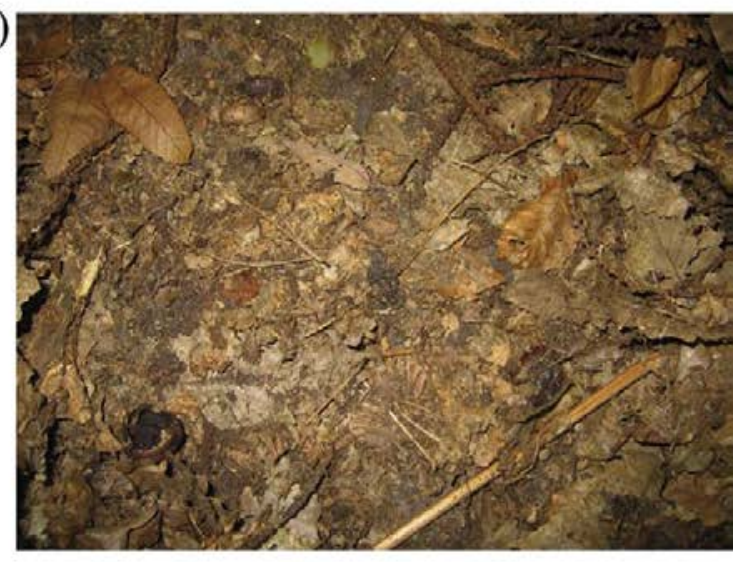


a)

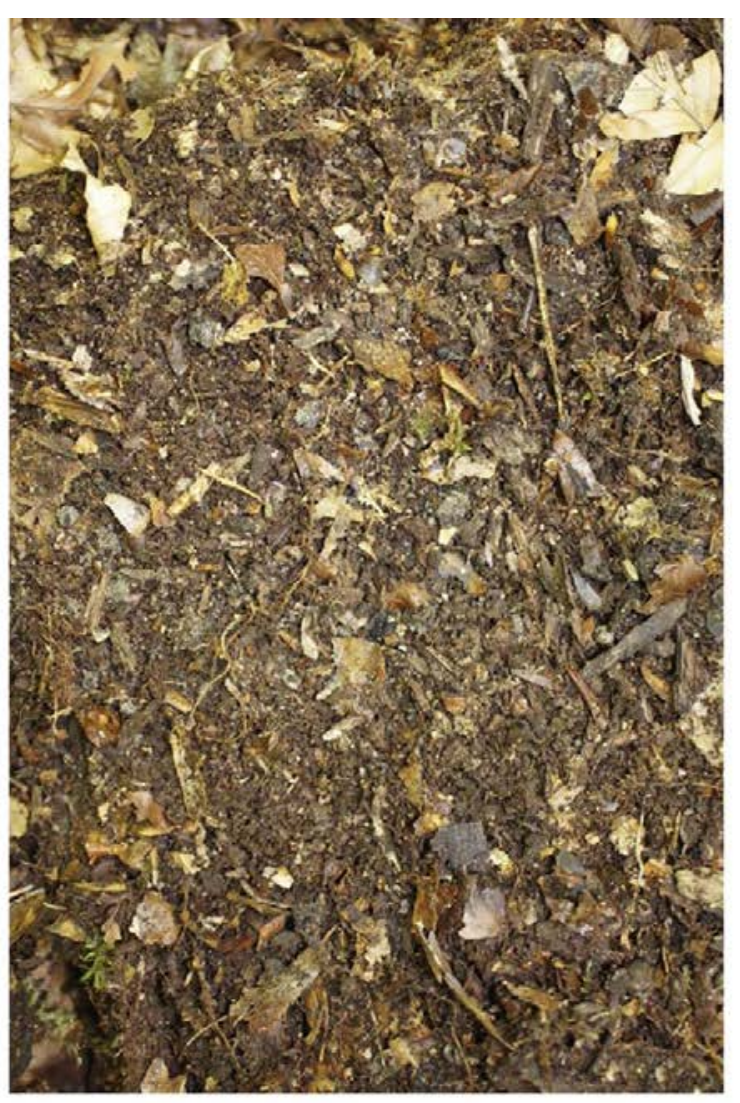

c)

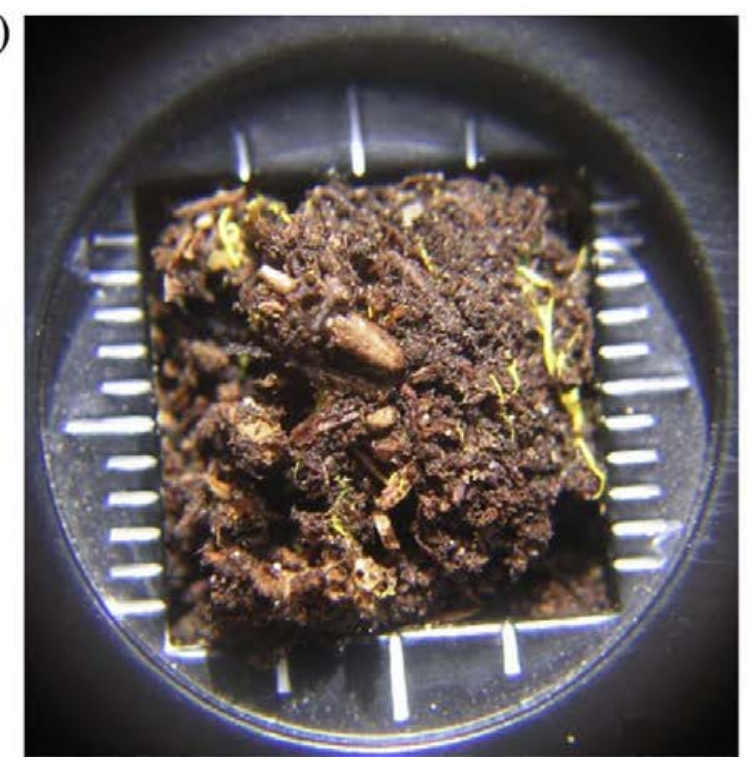

b)

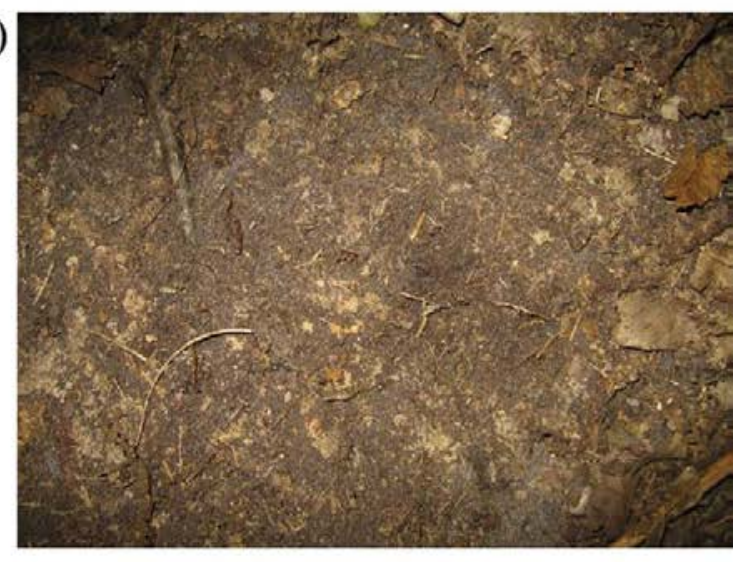

d)

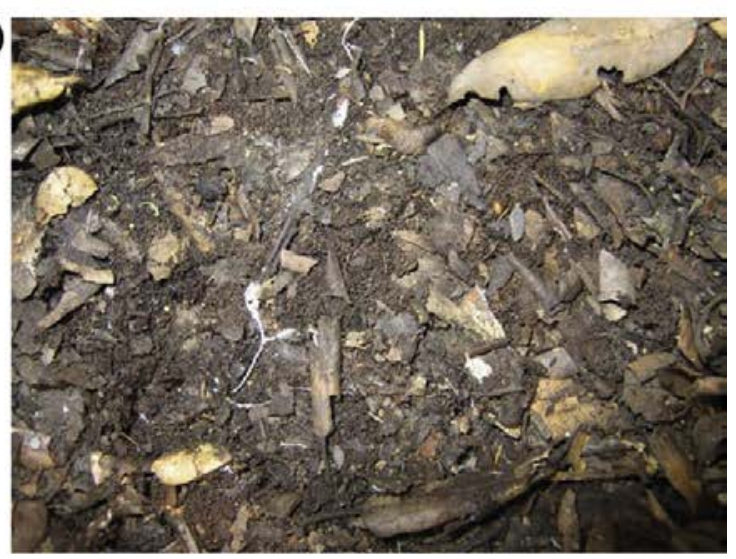

Fig. 7 
a)

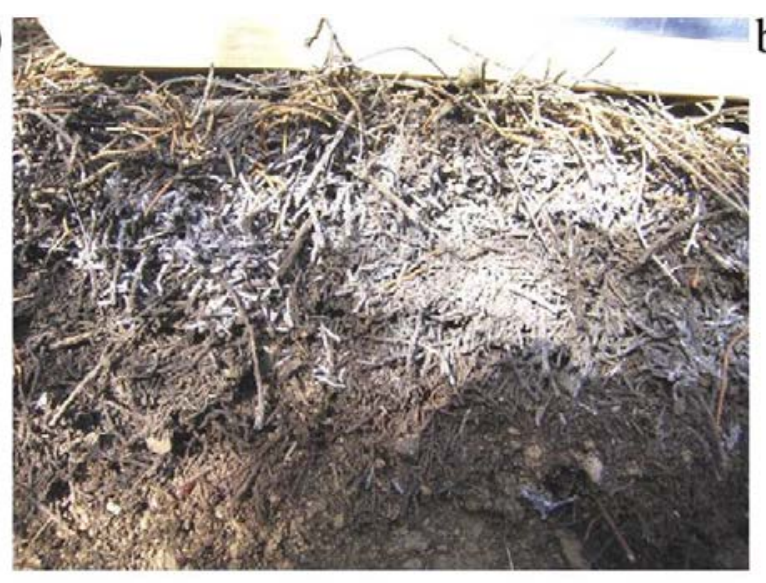

b)

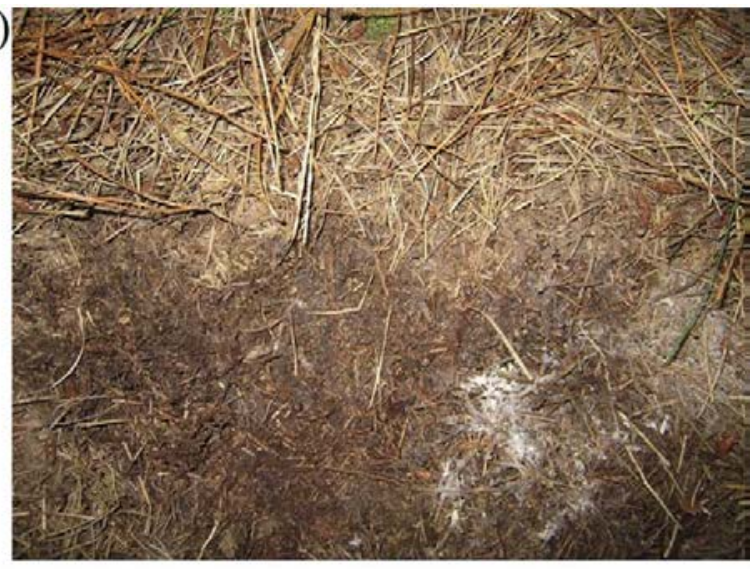

c)

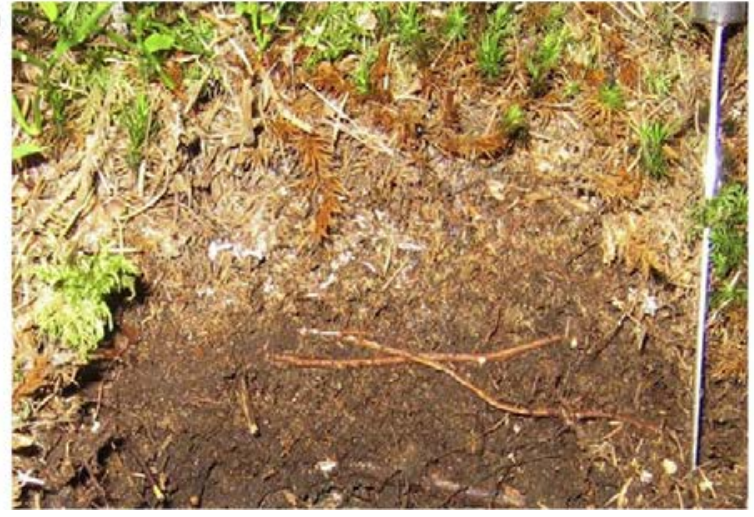

Fig. 8 
a)

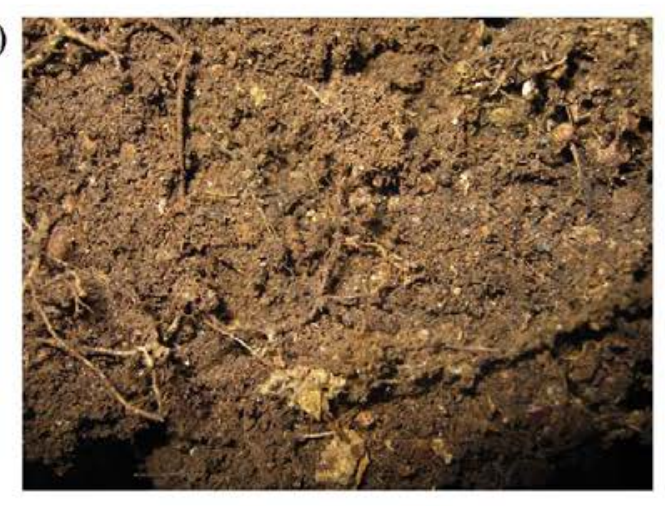

c)

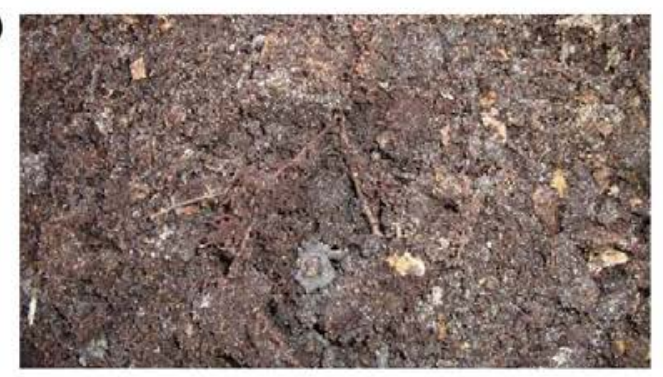

b)

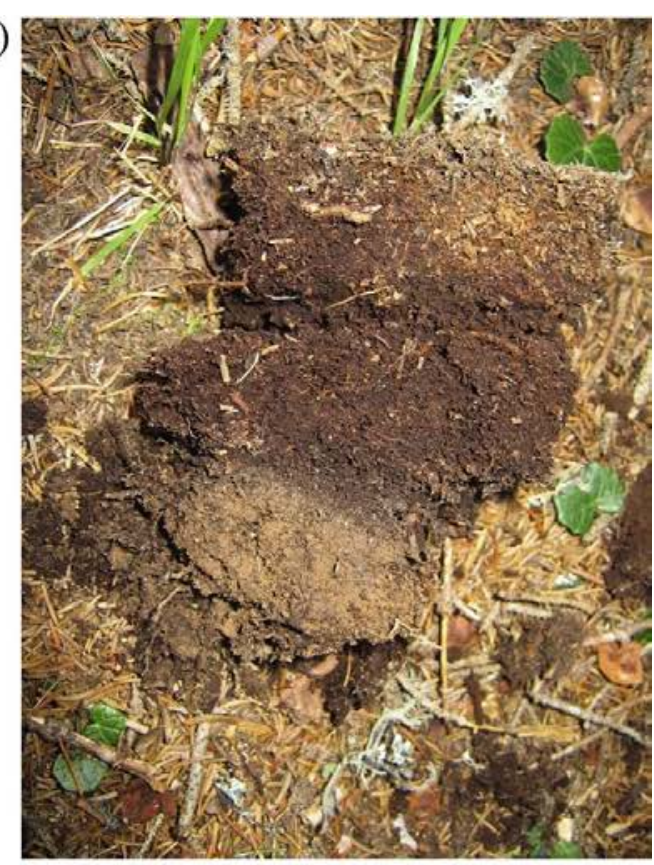

d)

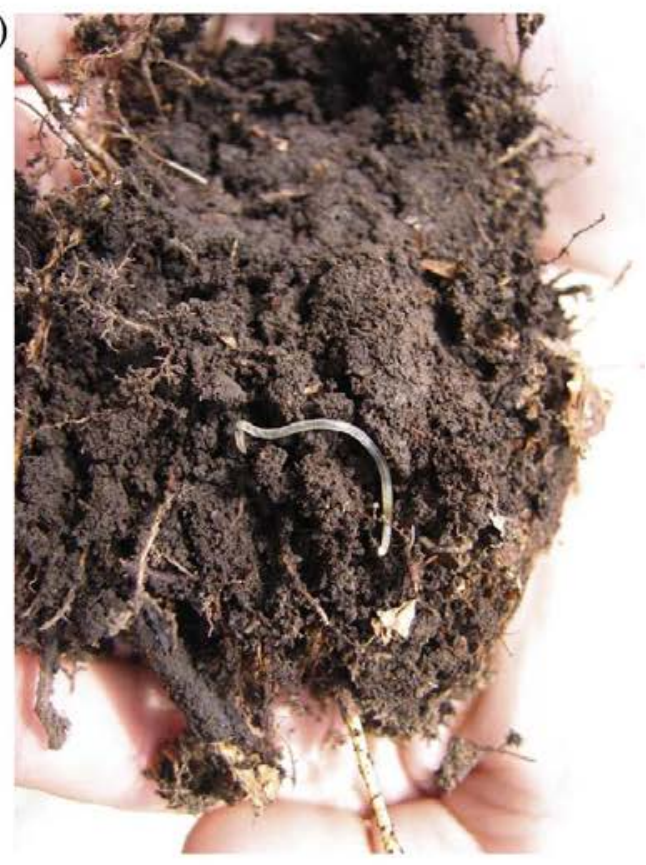

e)

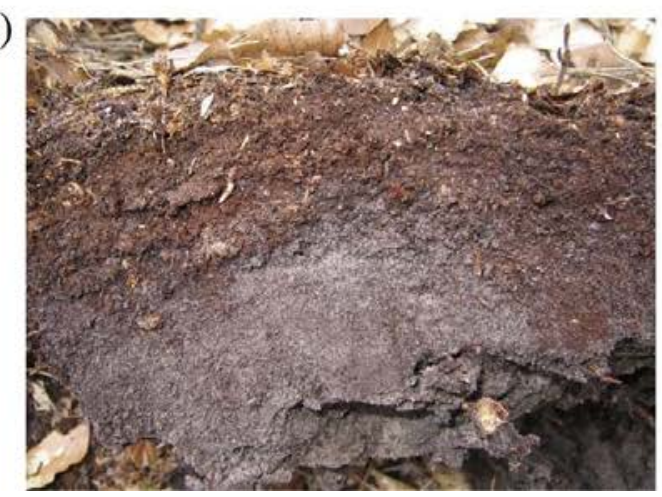

Fig. 9 


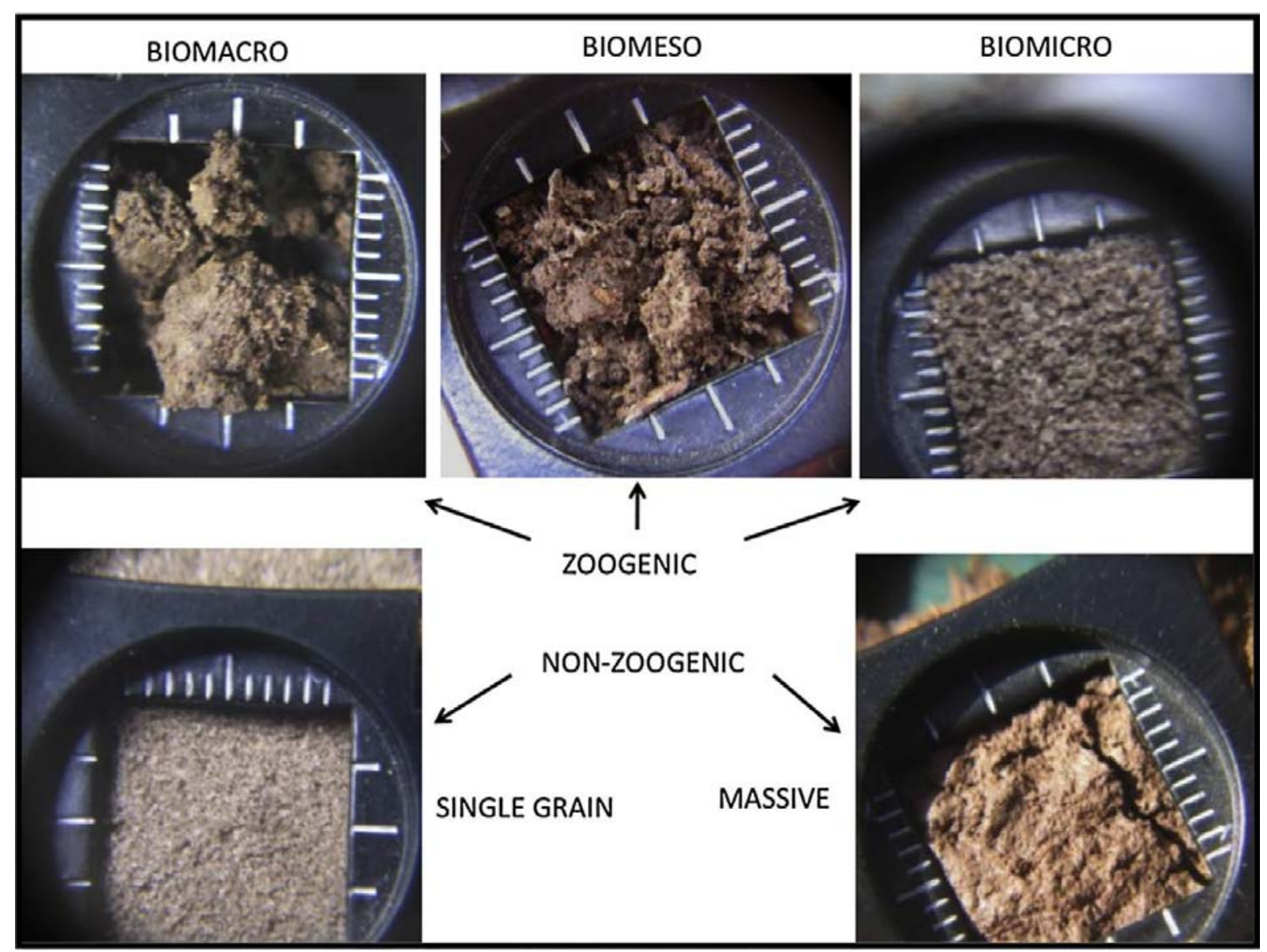

Fig. 10 
a)
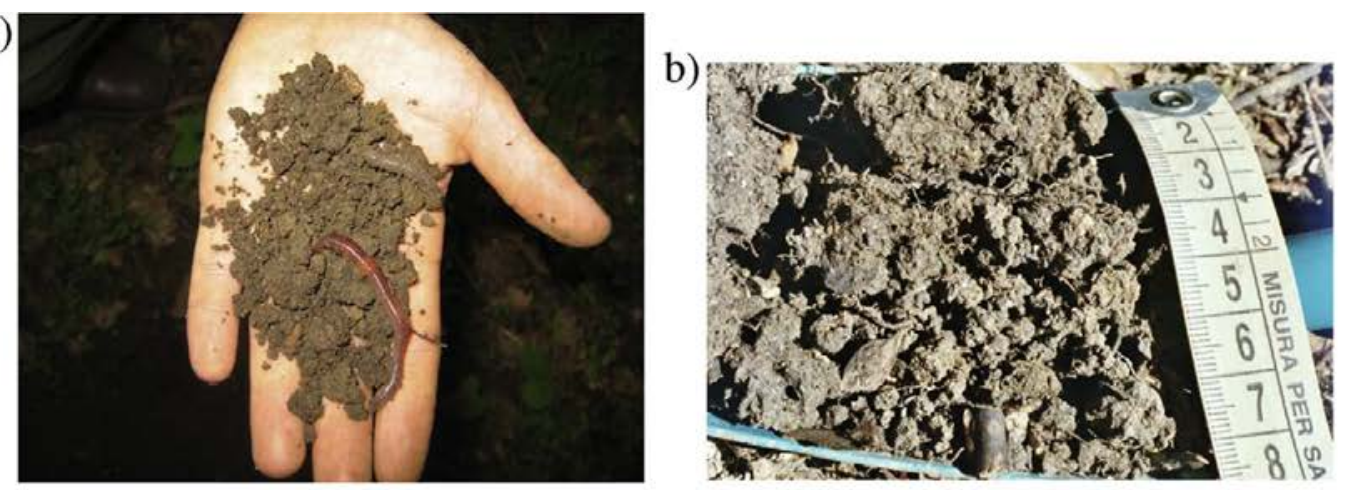

c)

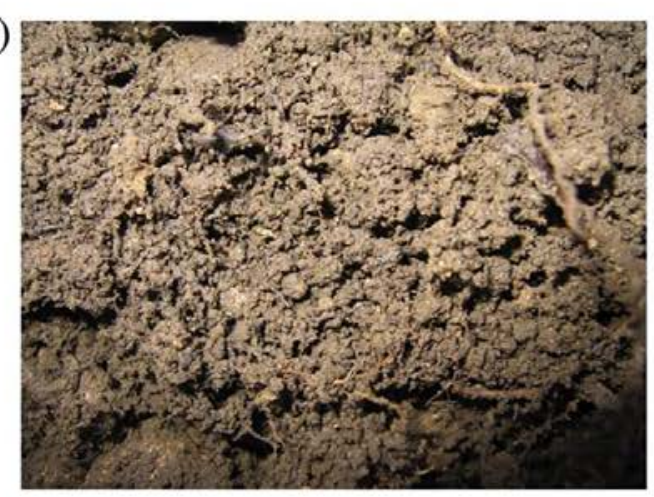

e)

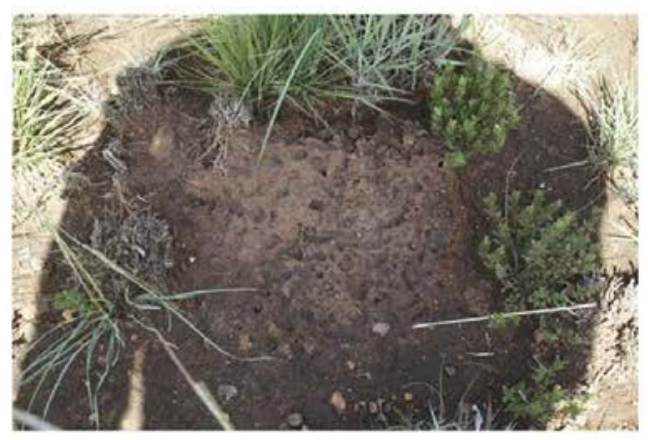

g)

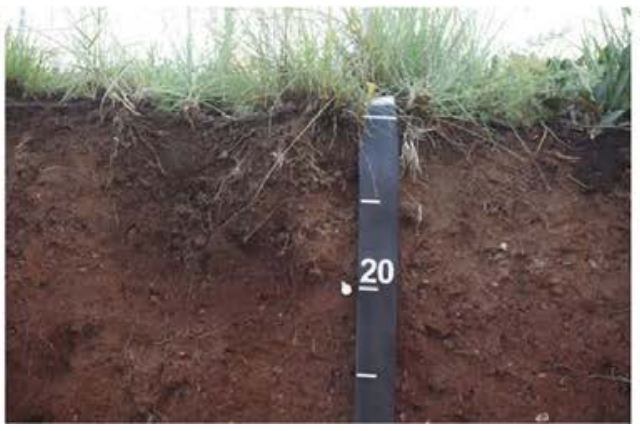

d)

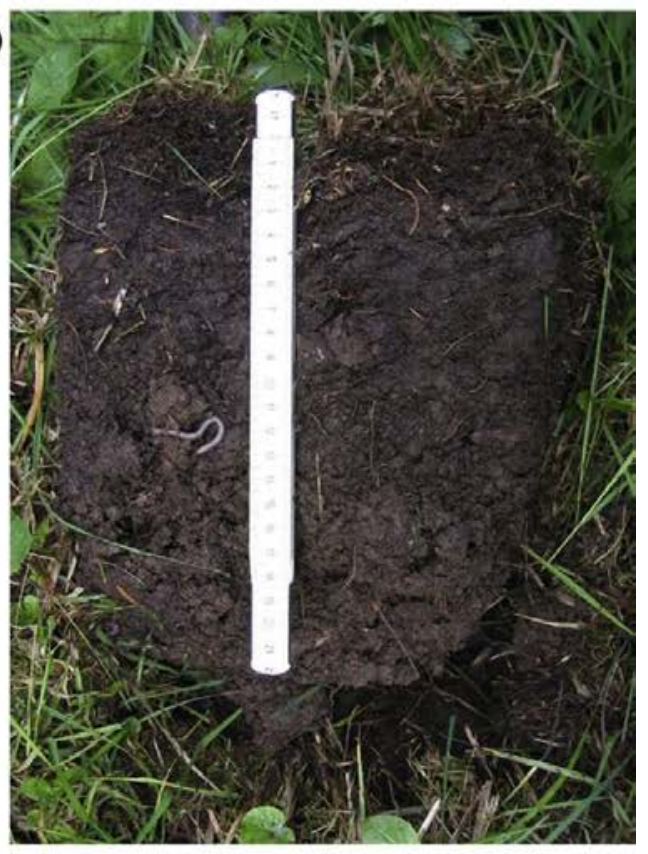

f)

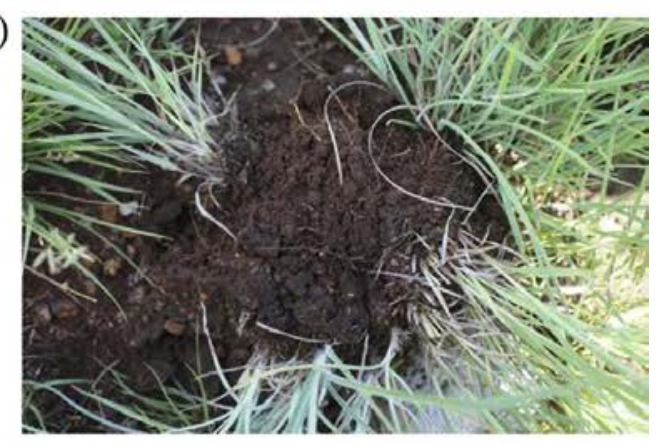

h)

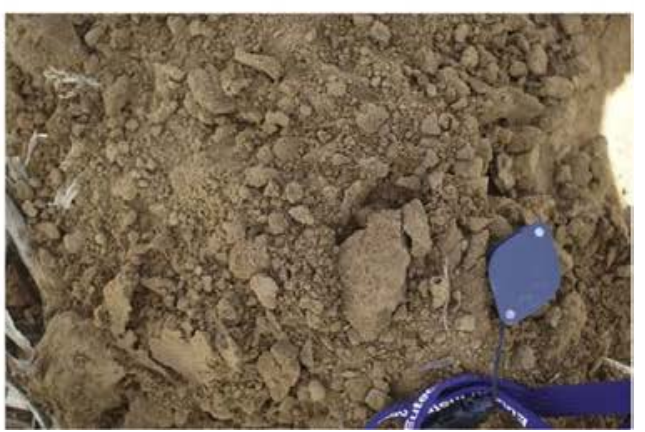

Fig. 11 
a)

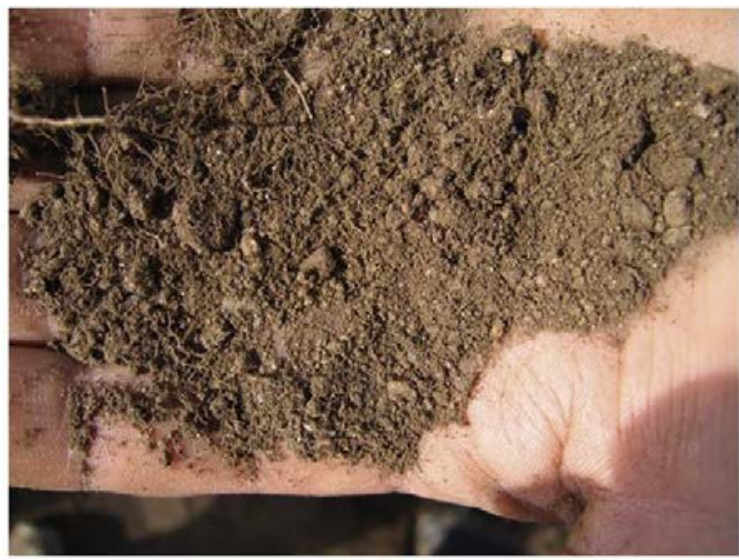

c)

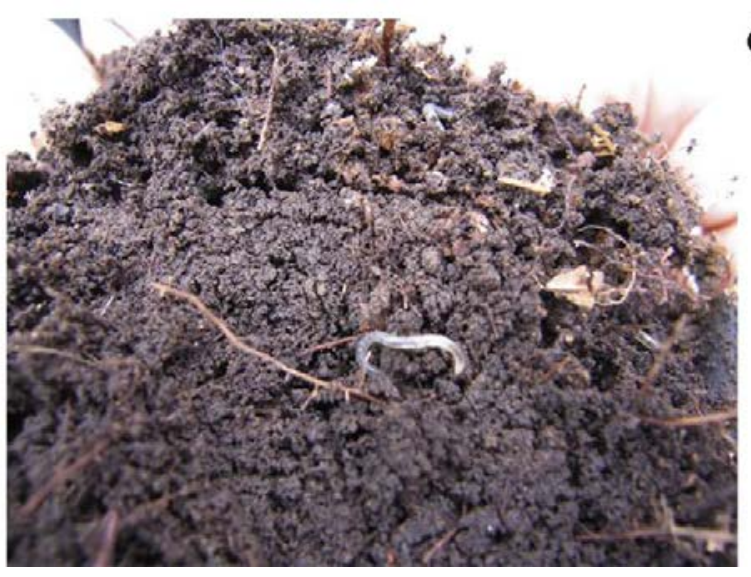

b)

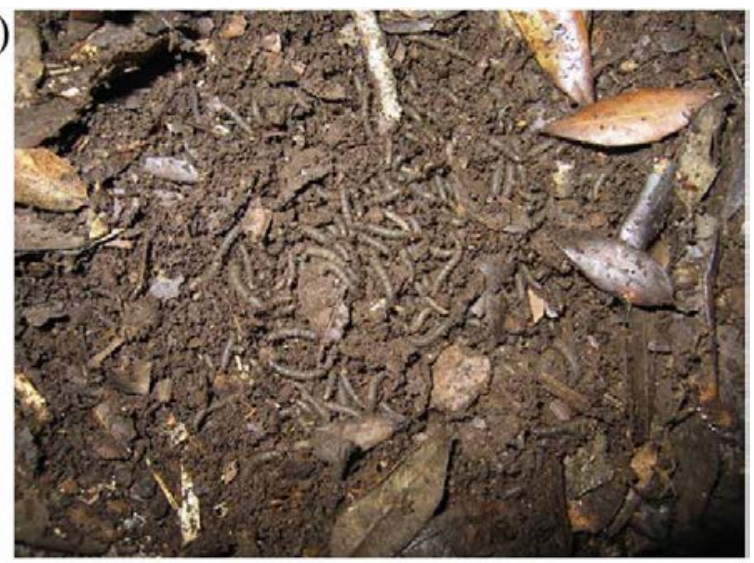

d)

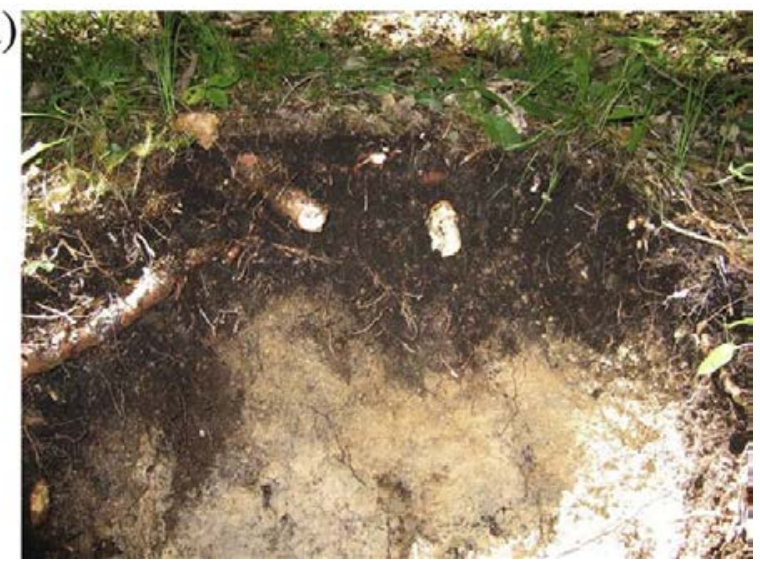

Fig. 12 
a)

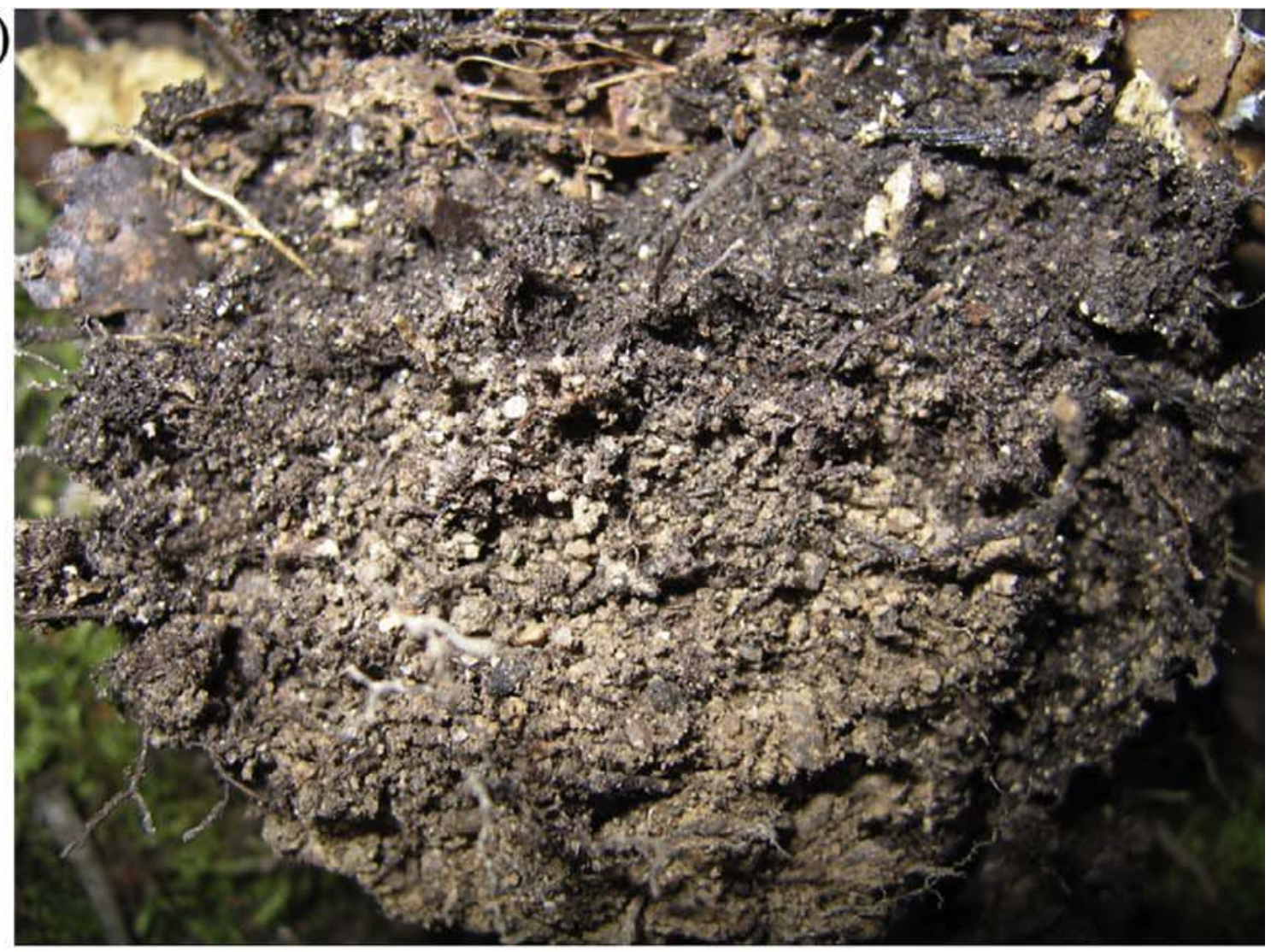

b)

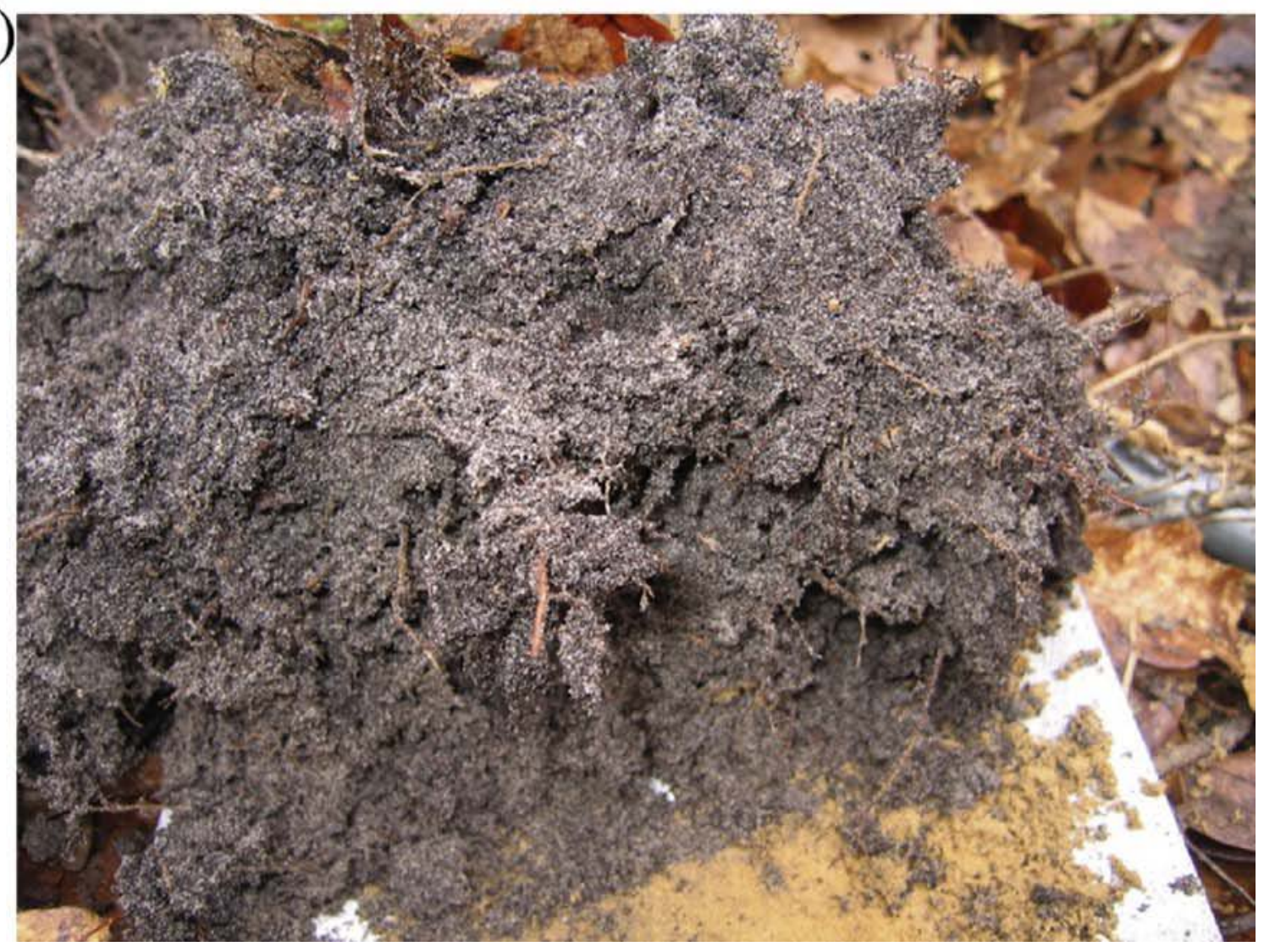

Fig. 13 


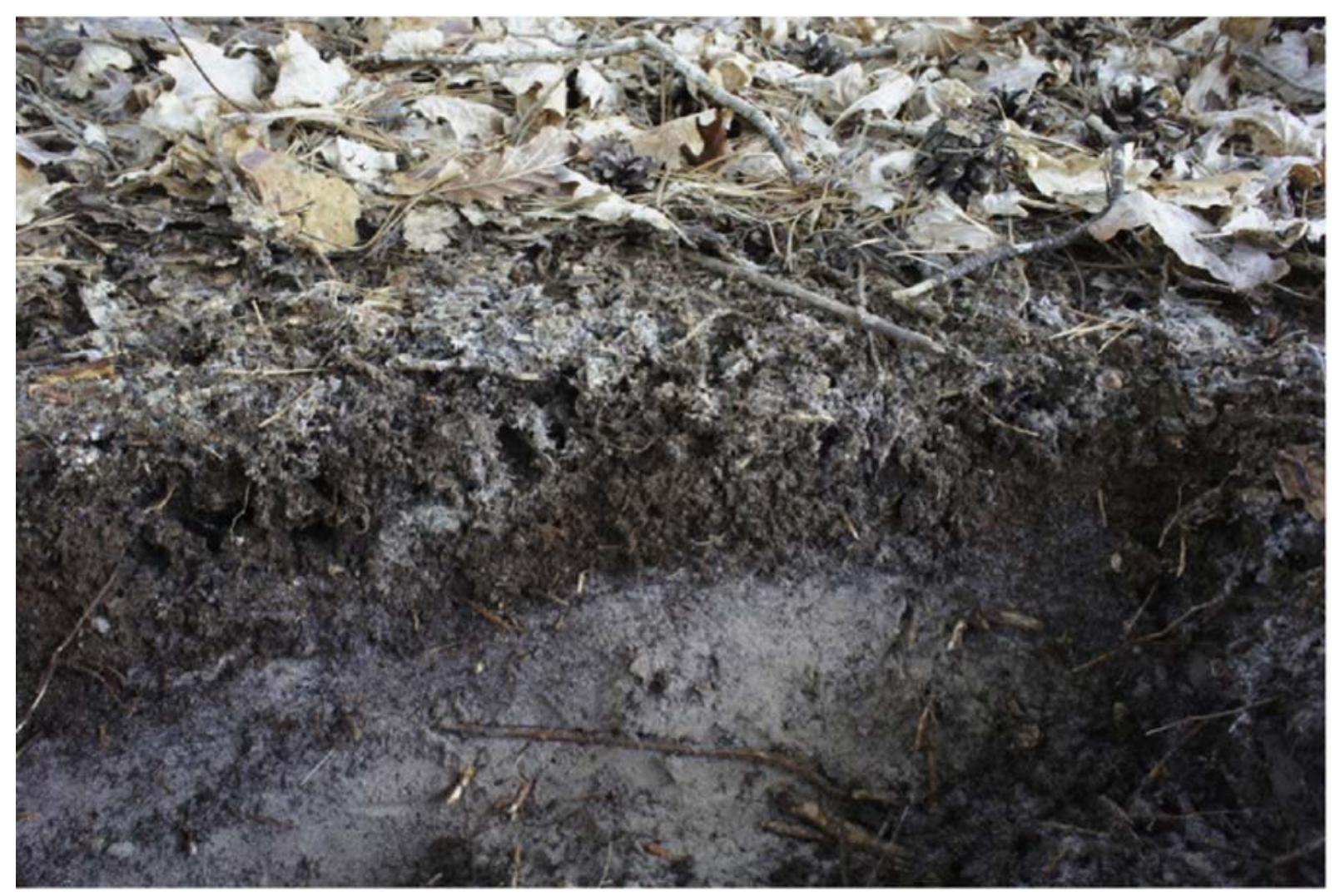

Fig. 14 


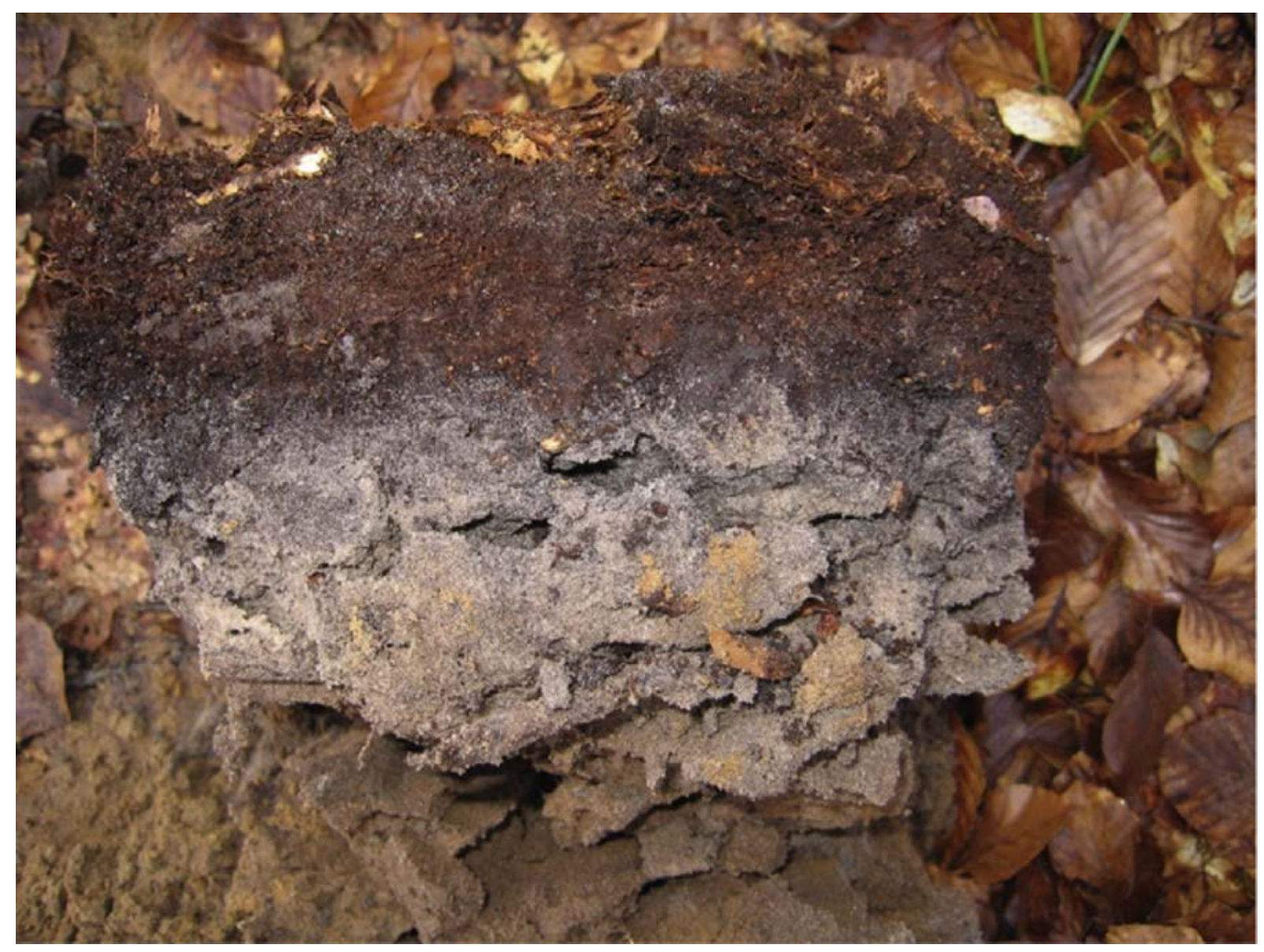

Fig. 15 


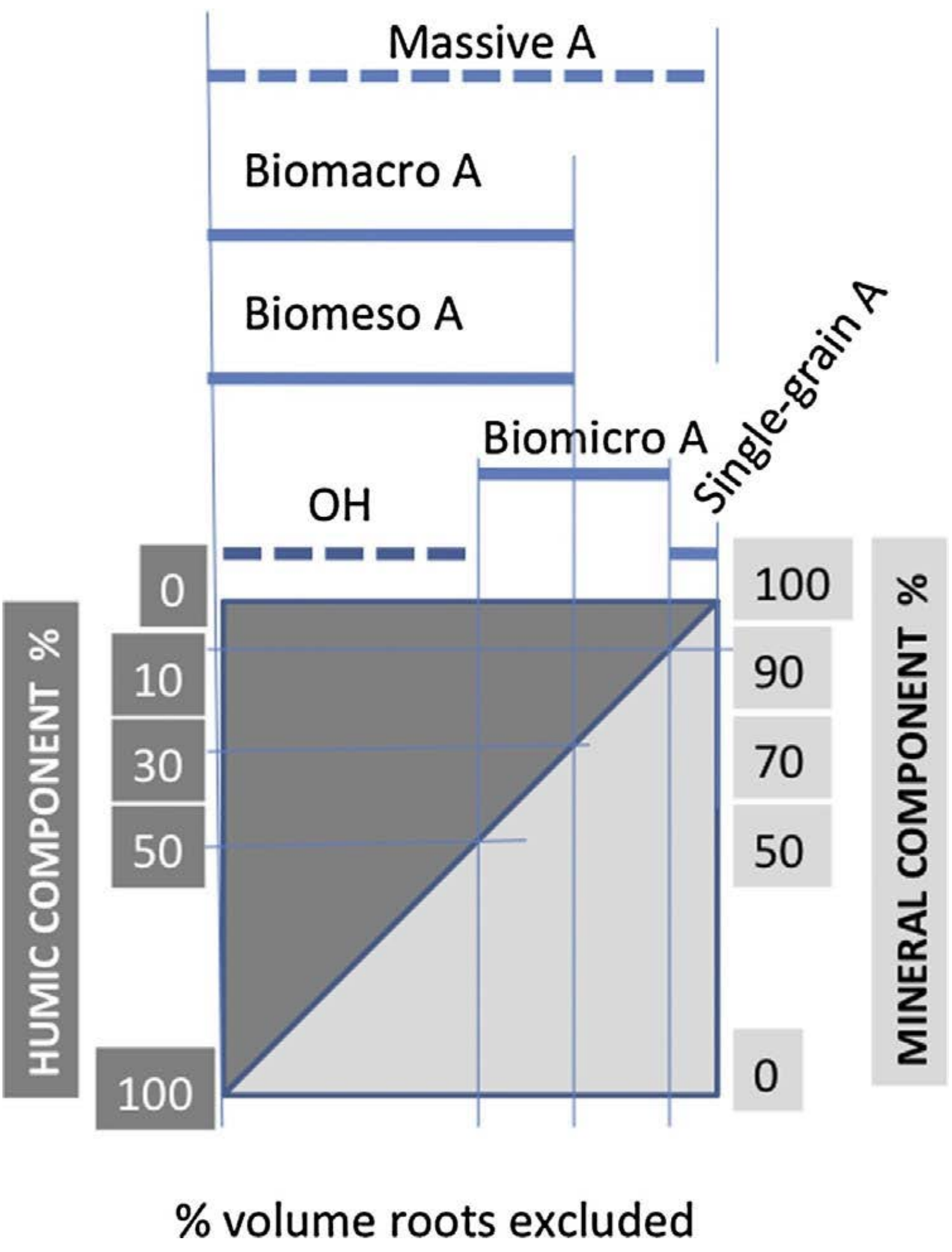

Fig. 16 


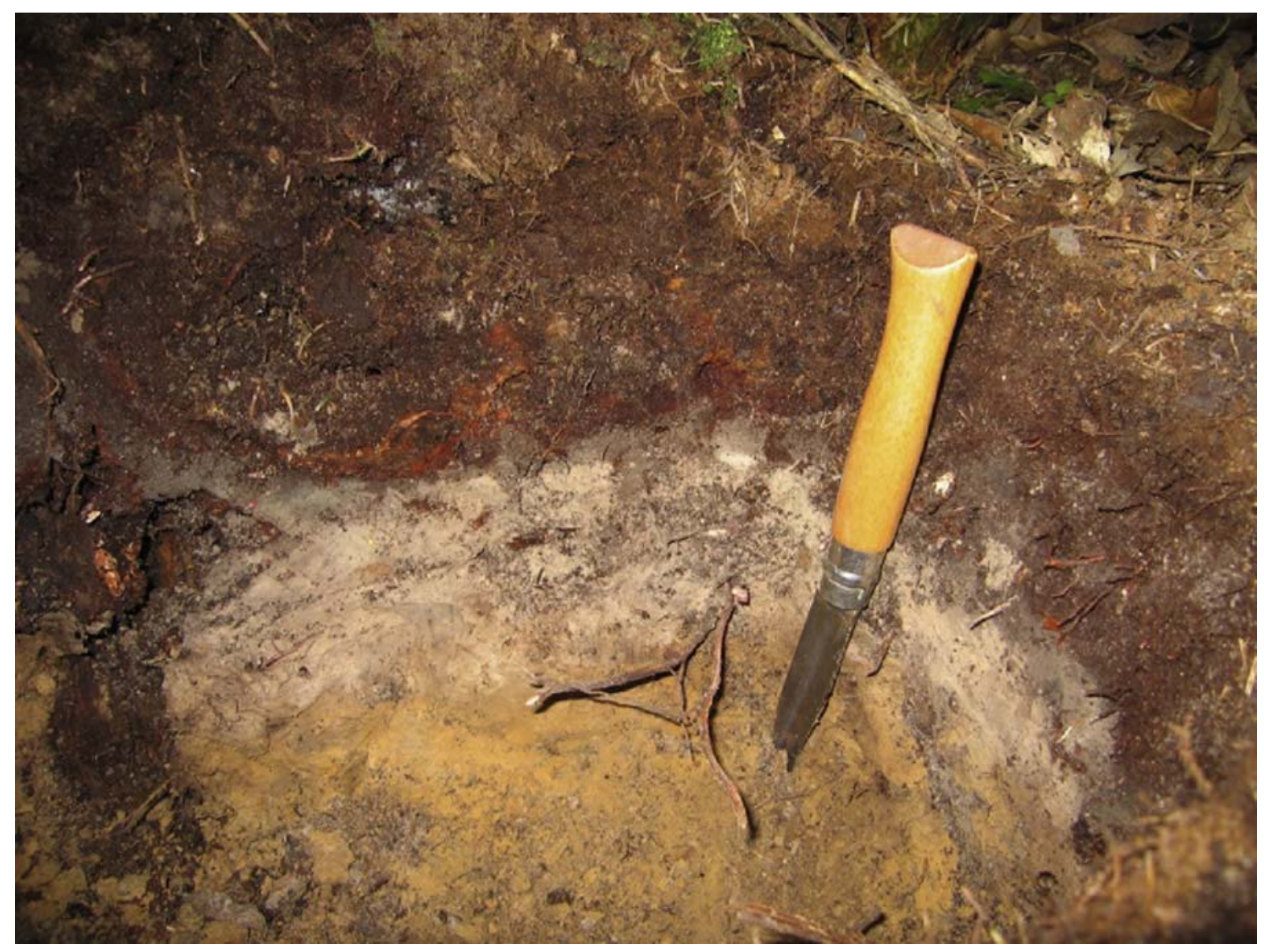

Fig. 17 


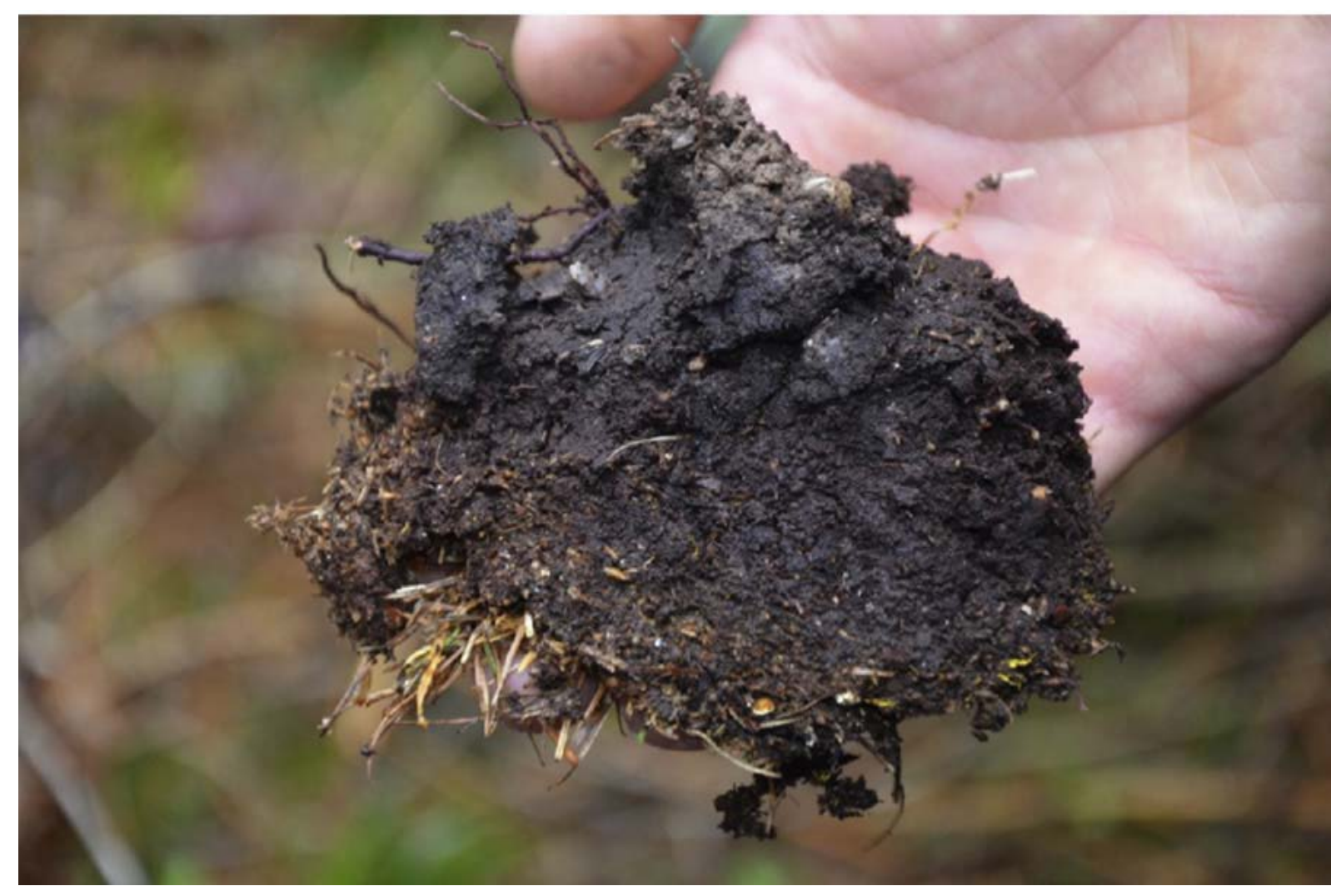

Fig. 18 


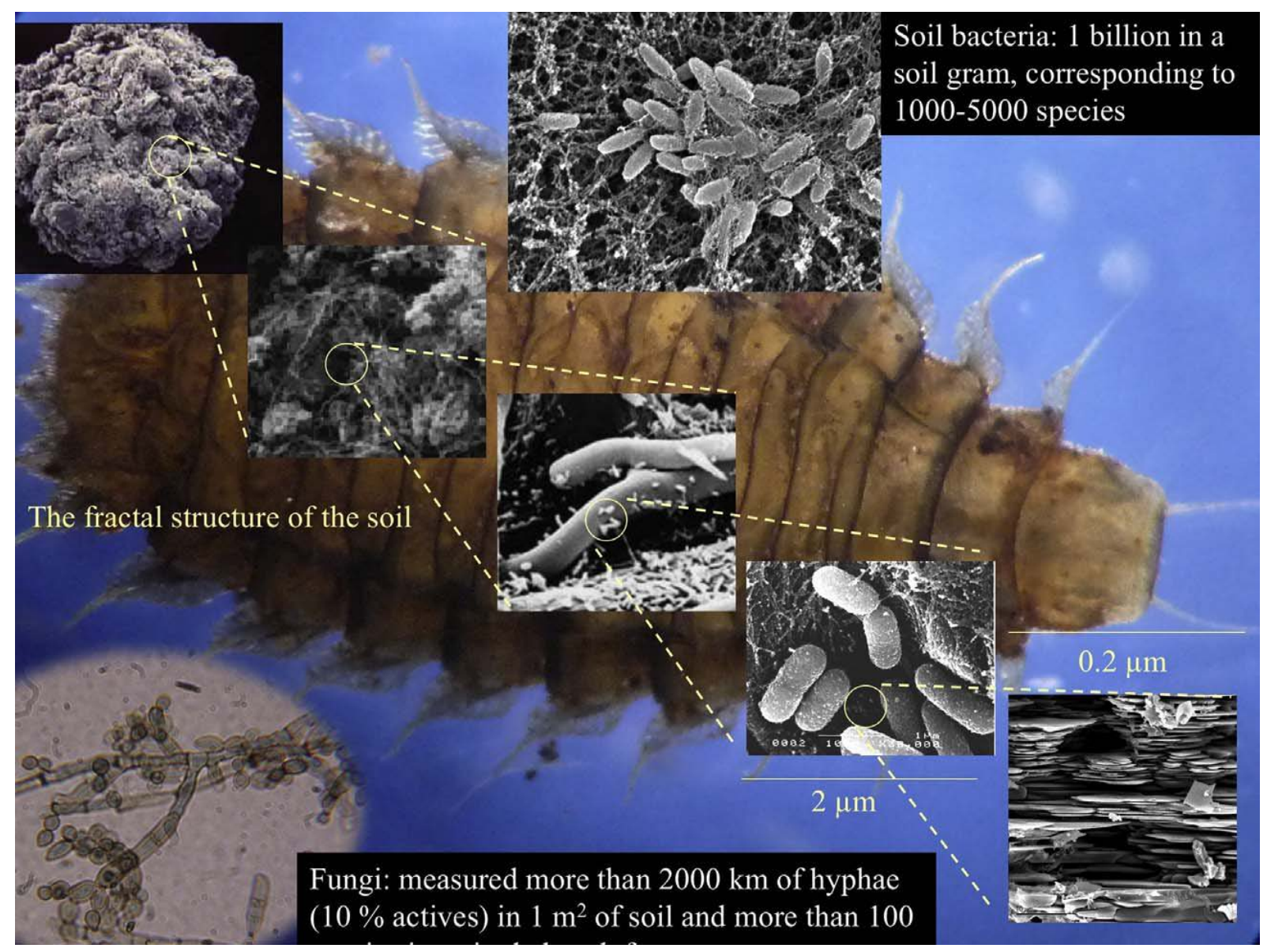

Fig. 19 


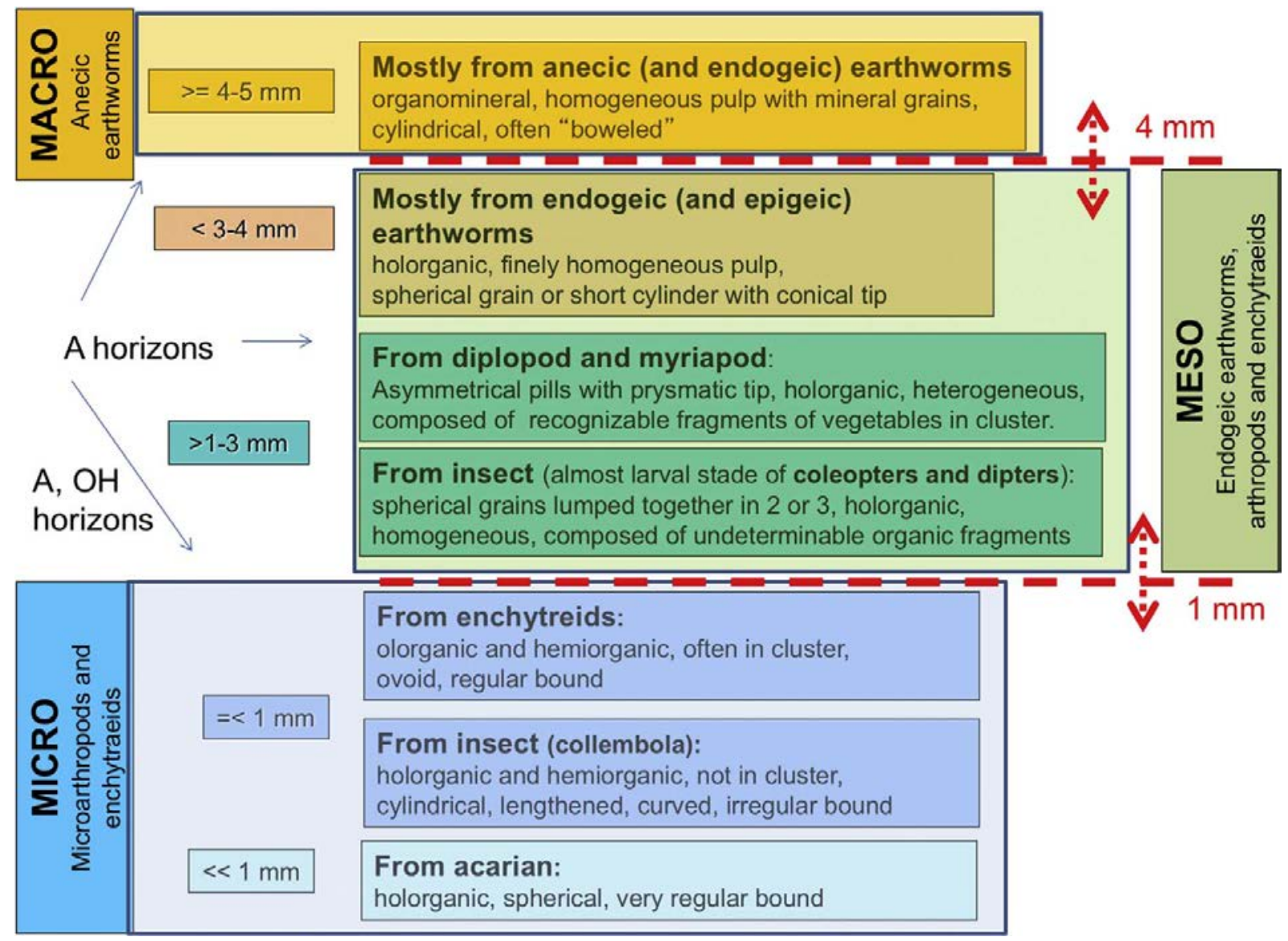

Fig. 20 


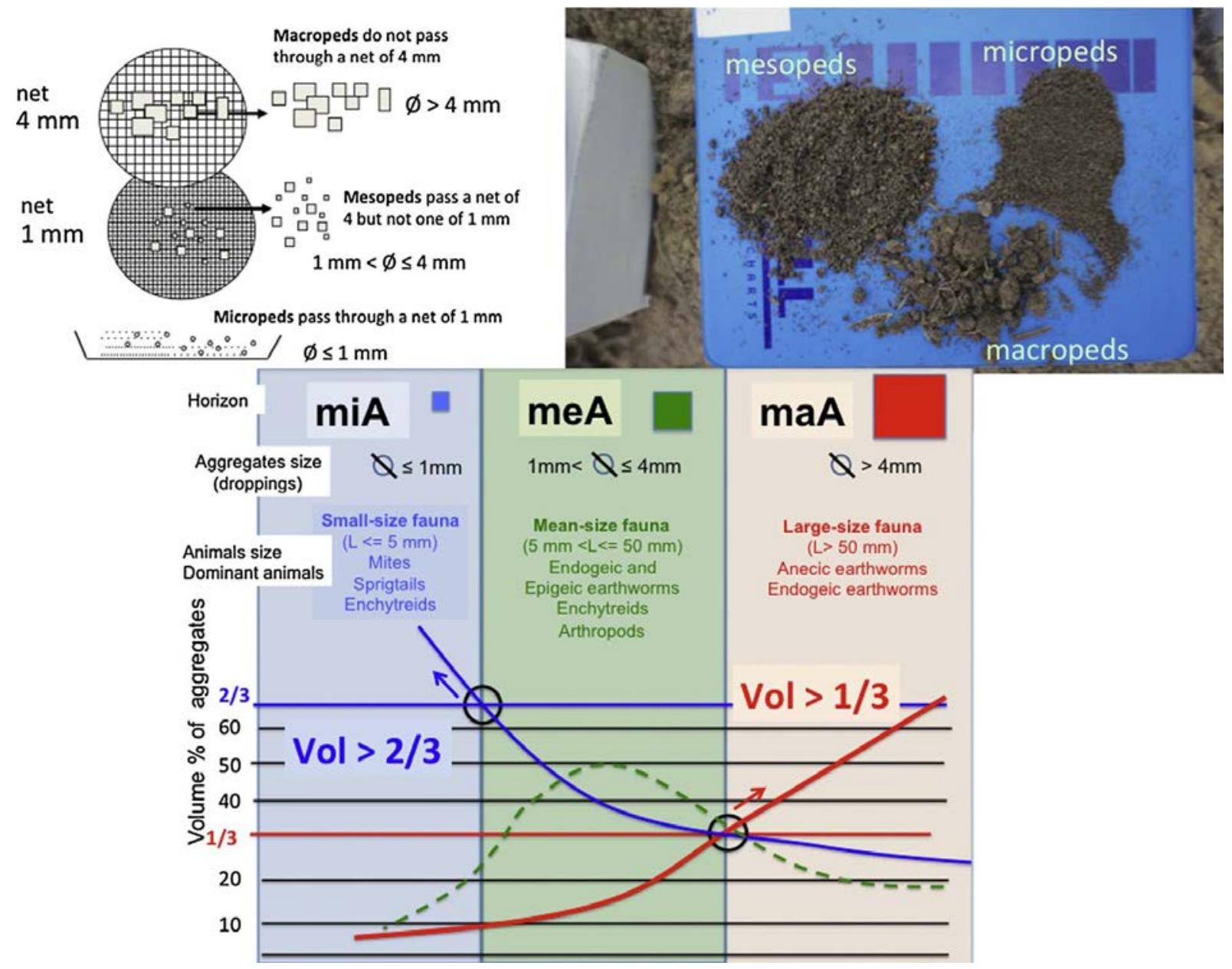

Fig. 21 


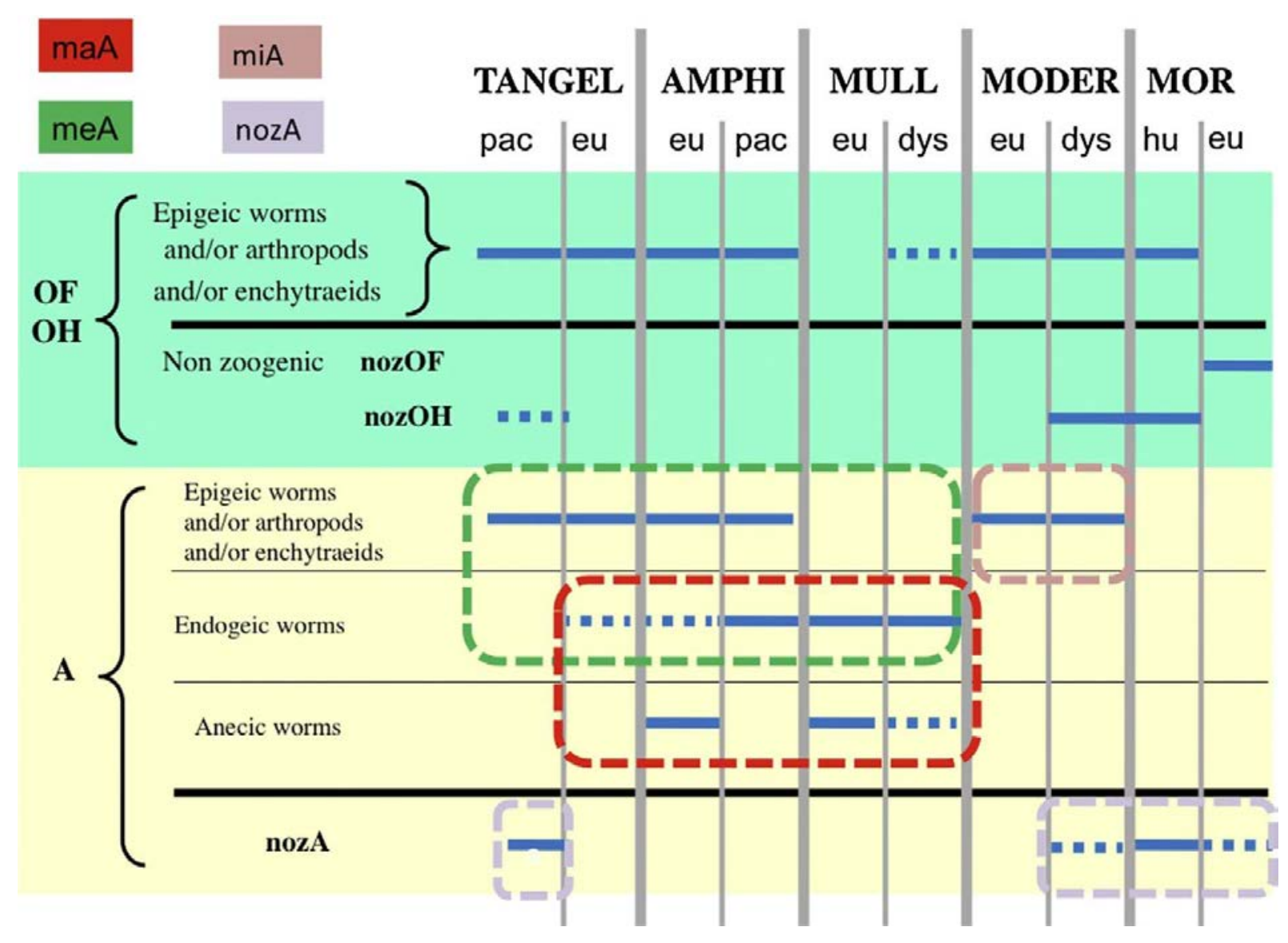

Fig. 22 


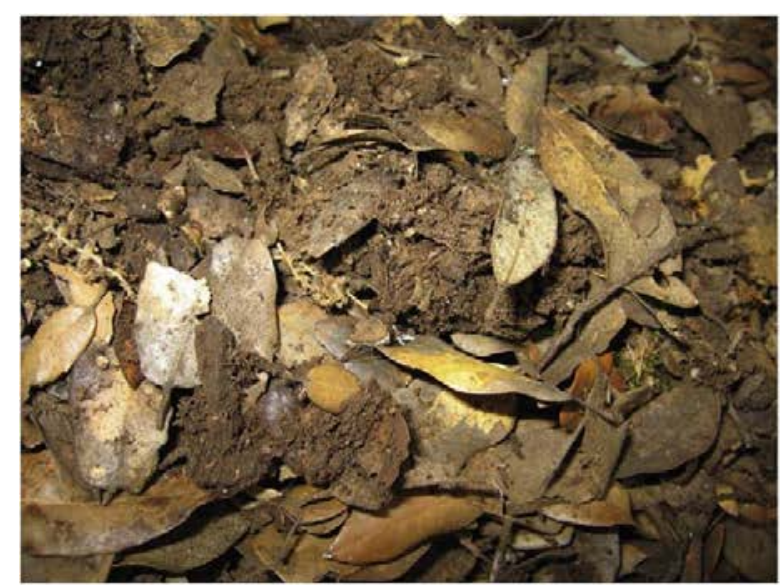

Fig. 23

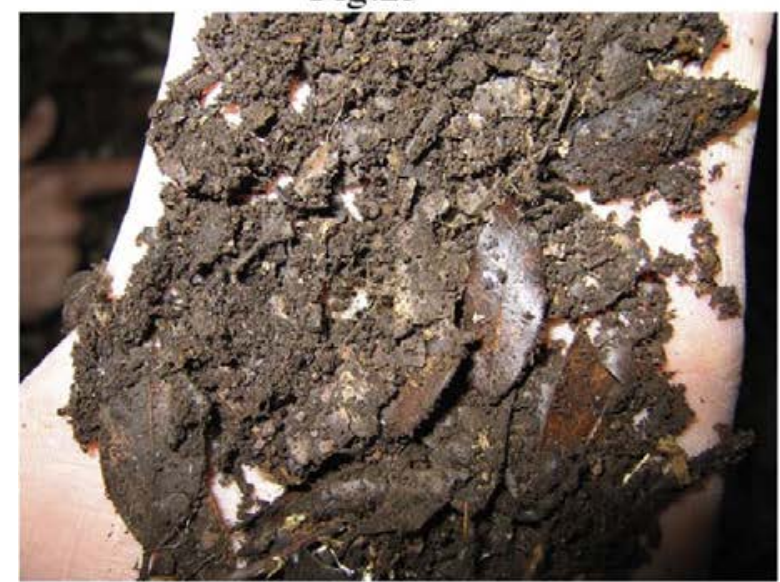

Fig. 25

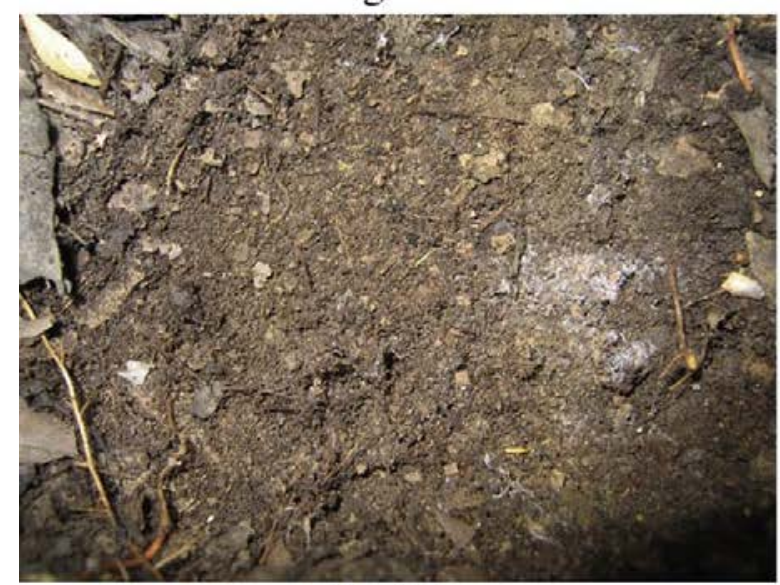

Fig. 27

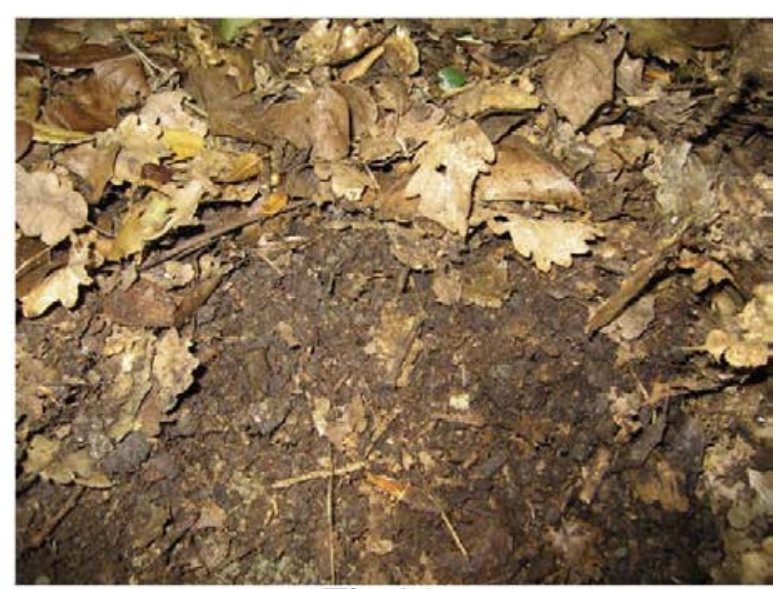

Fig.24

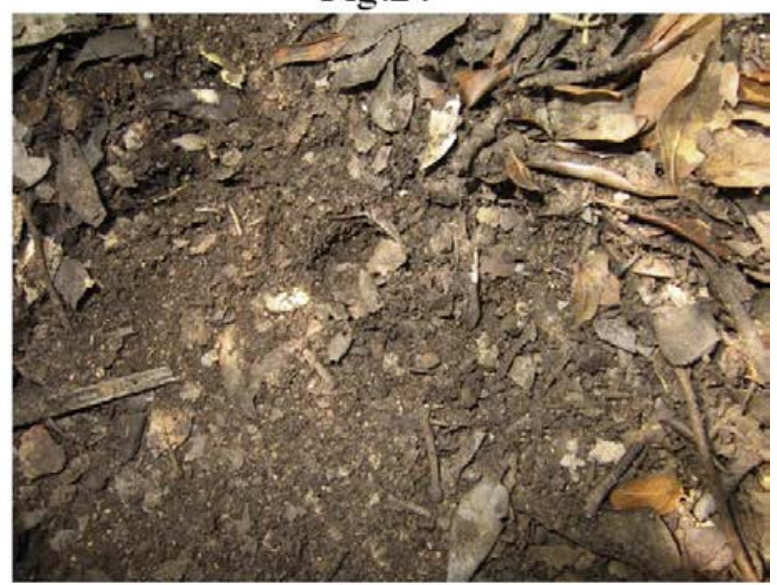

Fig.26

Figs. 23-27 


\section{Graphical symbols for components}

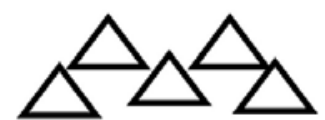

Intact litter (leafs, needles,...)

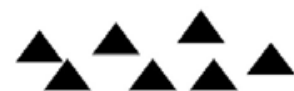

Fragmented litter

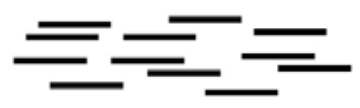

Matted lighter litter

$\because \quad$ Faecal pellets or/and unidentified organic particle,

biomicrostructure (microartropods, enchitreids): $\varnothing=<1 \mathrm{~mm}$ and organic-mineral ( $\bigcirc$ ) complexes, biomesostructure: $1<\emptyset<=4 \mathrm{~mm}$

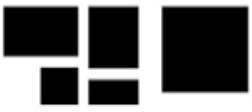

Matted organic particles or pieces, mycogenic biodegradation
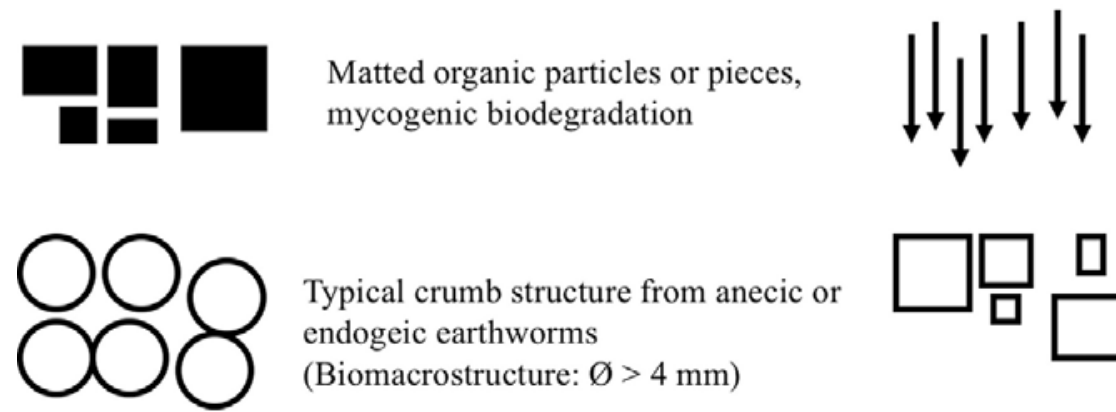

Typical crumb structure from anecic or endogeic earthworms

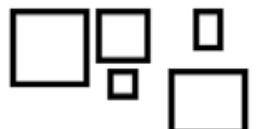

Mineral particles (Biomacrostructure: $\varnothing>4 \mathrm{~mm}$ )

\section{Examples of diagnostic horizons (using symbols)}

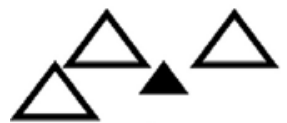

OLn

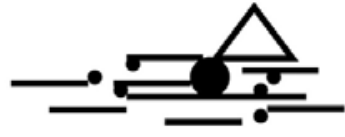

OLv

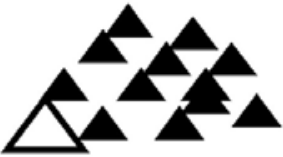

$\mathrm{OF}$

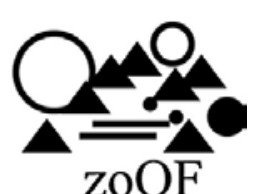

$\mathrm{zoOF}$

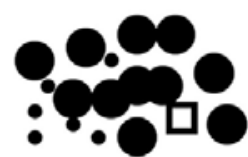

$\mathrm{zoOH}$

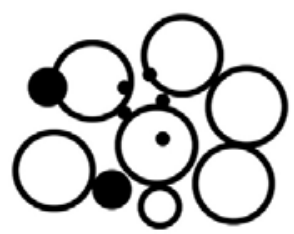

Amacro

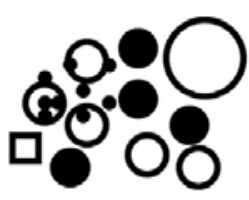

Ameso

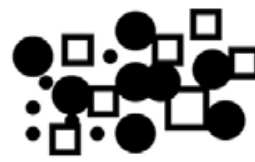

Amicro

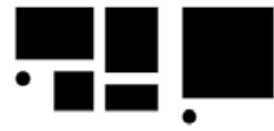

nozOF, $\mathrm{szoOH}$

Fig. 28 